\title{
1 Turgor-time controls grass leaf elongation rate and duration under 2 drought stress
}

3 Running head: Turgor-time controls grass leaf growth

4 Jonas R. Coussement ${ }^{1}$, Selwyn L. Y. Villers ${ }^{1,2,3}$, Hilde Nelissen ${ }^{2,3}$, Dirk Inzé2,3, Kathy Steppe ${ }^{1}$

$5{ }^{1}$ Laboratory of Plant Ecology, Department of Plants and Crops, Faculty of Bioscience

6 Engineering, Ghent University, Coupure links 653, B-9000 Gent, Belgium,

$7{ }^{2}$ Ghent University, Department of Plant Biotechnology and Bioinformatics, 9052 Ghent, 8 Belgium

$9 \quad{ }^{3}$ VIB Center for Plant Systems Biology, 9052 Ghent, Belgium

$10 *$ corresponding author: Jonas.coussement@ugent.be

11 Funded by: Funding was provided by the Research Foundation Flanders (FWO) under research program G024218N granted to KS and DI, supporting the postdoc work of JRC and PhD Fellowship strategic basic research 1 S03720N granted to SLYV.

\section{Abstract:}

The process of leaf elongation in grasses is characterised by the creation and transformation of distinct cell zones. The prevailing turgor pressure within these cells is one of the key drivers for the rate at which these cells divide, expand and differentiate, processes which are heavily impacted by drought stress. In this paper, a turgor-driven growth model for grass leaf elongation is presented which combines mechanistic growth from the basis of turgor pressure with the ontogeny of the leaf. Drought-induced reductions in leaf turgor pressure result in a simultaneous inhibition of both cell expansion and differentiation, lowering elongation rate but increasing elongation duration due to the slower transitioning of cells from the dividing and elongating zone to mature cells. Leaf elongation is therefore governed by the magnitude of, and time spent under, growth-enabling turgor pressure, a metric which we introduce as turgor-time. Turgor-time is able to normalise growth patterns in terms of varying water availability, similar to how thermal time is used to do so under varying temperatures. Moreover, additional inclusion of temperature-dependencies within our model pioneers a novel concept enabling the general expression of growth regardless of water availability or temperature. 
Keywords: turgor pressure, turgor-time, leaf elongation rate, grass, drought stress, leaf kinetics, division, elongation, mechanistic model, turgor-driven growth

Acknowledgments: We would like to thank Research Foundation Flanders (FWO) for funding this research.

\section{INTRODUCTION}

Achieving and maintaining food security represents one of the major global challenges in the face of a growing world population and changing climate. Both grasslands and grain crops play a fundamental role in reaching this goal, both as fodder and as the most important food source for human consumption (FAO 2014). Drought events have been observed to increase in both frequency and severity and will continue to do so even under conservative climate change scenarios (IPCC 2014). These events are projected to affect the majority of these global crop production systems, which can be a major cause of reduced yields. Even at moderate rates of drought stress, grass leaf area expansion is reduced due to extreme drought sensitivity of the leaf growth process (Bradford \& Hsiao 1982). In perennial grasses, this strongly affects production due to decreased rates of refoliation after cutting or grazing (Durand, Onillon, Schnyder \& Rademacher 1995). In annual grain crops, it leads to decreased growth rates, exacerbated by a decreased rate of development. Effective breeding for drought tolerance will therefore play a critical role for tackling the impact of drought events in the production of both perennial grasses (Norton, Malinowski \& Volaire 2016) and grain crops (maize (Gong, Wu, Zhang, Chen \& Wang 2015), rice (Luo 2010), wheat and barley (Munns, James, Sirault, Furbank \& Jones 2010)). Large-scale phenotyping of new genotypes is often difficult, due to inconsistent performance under different levels of drought or management (genotype $\times$ management $\times$ environment; $\mathrm{G} \times \mathrm{M} \times \mathrm{E}$ ) and difficulties in obtaining representative field trials due to the possible absence of drought in any given year (Cooper, Gho, Leafgren, Tang \& Messina 2014). Understanding the physiological basis of drought-tolerant traits and their effect on crop growth and yield performance has the potential to 
identify those traits that are most relevant for better adaptation (van Eeuwijk et al. 2019) leading towards a focussed breeding approach.

A better understanding of the effects of water limitations on plant growth can be gained through multiscale modelling (Benes et al. 2020), whereby plant-environment interactions can be combined with a mechanistic growth model at the individual organ scale. Specifically, a functional-structural plant model (FSPM) has the unique potential to describe the growth and development of the entire plant through a combination of both physiological and architectural traits, which has a double function. Firstly, such a model can be used to dissect a given phenotype into an underlying set of traits and mechanisms at play (Tardieu, Cabrera-Bosquet, Pridmore \& Bennett 2017). Secondly, it can be used to make predictions on how these traits and mechanisms might interact under a plethora of environmental conditions, of which the impact is not always intuitive (Tardieu \& Parent 2017), and where a model would allow for a thorough search towards a hypothetical ideotype (Sarlikioti et al. 2011). However, the development of a whole-plant FSPM carries significant challenges and requires the most fundamental processes contributing to growth and development to be understood and incorporated. One of these crucial aspects is the effect of water limitation on leaf elongation rate, which has not yet been modelled within this context and is a necessary step towards the development of a drought-sensitive FSPM for any grass species. Leaf kinetics in terms of water availability have been previously studied at a fundamental level using the Lockhart (1965) equation, whereby turgor pressure is the driver of cell expansion in the leaves of many species (e.g., wheat (Zubairova et al. 2016), barley (Fricke \& Flowers 1998), maize (Cramer \& Bowman 1991; Cramer 1992)). However, these studies do not incorporate the ontogenetic changes that occur throughout a grass leaf life cycle, whereby three distinct cellular zones are formed (Skinner \& Nelson 1995). Grass leaves are initially formed as a pool of dividing cells aptly named the division zone (DZ). After a period of time, the grass leaf cells positioned at the end of this zone undergo a 
elongation and forming a new zone, referred to as the elongation-only zone (EOZ), where the bulk of leaf expansion takes place. Gradually, the cells within this zone transition into mature cells forming the mature zone (MZ), which gradually encompasses the entire leaf eventually halting leaf expansion.

These ontogenetic changes were first included in a model by Durand et al. (1999) and later expanded by Fournier et al. (2005) whereby important parameters regarding the growth and differentiation of tissue zones within the elongating leaf were incorporated. However, the growth and transition rates within this model were based on a linear relation with thermal time without an underlying mechanistic growth model. The widely used concept of thermal time (Trudgill, Honek, Li \& Van Straalen 2005) is based on the observation that the rate of growth and development within plants are largely linearly related to temperature within a species-specific upper and lower bound (i.e. the base temperature $T_{b}$; under which growth and/or development halts). If this range encompasses the majority of perceived temperature ranges in which these plants grow, it allows a uniform description of their growth and development rate (usually under the form of a sigmoid growth curve (e.g., Yin et al. 2003)) in terms of thermal time, making it valid for application under any temperature treatment within the linear range.

The effects of drought on growth and transition rates distort this linear relationship with temperature, as thermal time is not affected by drought. It is widely reported that even mild drought stress results in a reduction in $\mathrm{DZ}$ and $\mathrm{EOZ}$ length, but also in a significant increase in growth duration (e.g., in maize (Avramova et al. 2017; Nelissen et al. 2018)). A dependency of both the elongation rates and the transition rates on water limitations is therefore warranted. A mechanistic grass leaf growth model thus requires a combination of the turgor-driven growth aspect of the Lockhart (1965) equation with the ontogenetic aspects of Durand et al. (1999) and Fournier et al. (2005), which is introduced in this paper. In a similar manner to how growth expressed in thermal time represents a linear relationship with the perceived temperature sum of the plant, the irreversible part of the Lockhart equation essentially describes a linear growth relationship with the perceived "growth-enabling turgor" sum. 
The "growth-enabling turgor" is defined as the cumulative sum of effective turgor above the threshold turgor. The threshold turgor acts as a similar baseline as $T_{b}$, as it represents the cut-off point under which growth and development halts. Using this approach, growth is essentially expressed in terms of perceived turgor, or "turgor-time", which enables normalised growth expression under various treatments of water availability, similar to how thermal time is used to normalise the expression of plant growth over a variety of temperature treatments under well-watered conditions.

Here, we introduce this new concept, named "turgor-time", to represent the expression of both the growth rate and the transition rates of the individual leaf zones in terms of turgor pressure conditions in a novel functional-structural leaf model for grass leaf elongation. The model provides a mechanistic integration of grass leaf elongation in terms of water availability, carbon availability, and leaf ontogeny. Differences in elongation rate between tissue zones were captured by differences in cell wall extensibility which, in turn, represent the different cell wall structure of these zones. As a result, the parameters describing the leaf elongation rate (LER) relate directly to cell wall kinetics and leaf ontogeny. Ideally, these parameters would represent direct translations of genotypic traits which would have the benefit that such a parameter set, combined with our model, could be used for phenotyping, in order to better understand and optimise breeding efforts towards drought tolerance in future applications. This only holds true if the model parameters are insensitive to drought, and thus are valid in both control and drought conditions for a certain genotype. To evaluate this hypothesis, a case study was performed on maize (Zea mays L.), whereby a kinematic maize leaf data set for a control group and a group submitted to mild drought stress was compared to model simulations. Furthermore, theoretical simulations were conducted to evaluate if the turgor-driven growth concept is able to reconcile the effects of both sugar and water availability on leaf ontogeny, elongation rate and duration and thus, coincide with literature reports of drought stress on leaf elongation. To do so, various hypotheses with regards to diurnal variation in leaf soluble sugar content, soil and atmospheric drought stress, temperature, and their effects on the mechanism underlying leaf elongation were tested. 


\section{MATERIALS AND METHODS}

\subsection{THE MODEL}

The model from Durand et al. (1999) describes the ontogeny of a grass leaf through the progression of three tissue zones. The leaf is initiated, consisting solely of the division zone (DZ), where new cells are initiated. After a set thermal time $\left(\mathrm{t}\left[{ }^{\circ} \mathrm{Cd}\right]\right)$, cells from the $\mathrm{DZ}$ are transformed into rapidlyelongating cells which form the elongation-only zone (EOZ). Slowly, at the distal end of the EOZ, cells mature and form the mature zone (MZ) where the elongation rate of the cells is zero and growth no longer takes place. The length of each of these zones is given by $D_{z}[m], E_{o z}[m]$ and $M_{z}[m]$, respectively. The progression of these leaf zones was captured by the following set of differential equations:

$$
\begin{gathered}
\frac{\mathrm{dD}_{\mathrm{z}}}{\mathrm{dt}}=\mathrm{k}_{1}(1-\mathrm{a}) \mathrm{D}_{\mathrm{z}} \\
\frac{\mathrm{dE}_{\mathrm{oz}}}{\mathrm{dt}}=\mathrm{k}_{1} \mathrm{aD}_{\mathrm{z}}+\mathrm{k}_{2}(1-\mathrm{b}) \mathrm{E}_{\mathrm{oz}} \\
\frac{\mathrm{dM}_{\mathrm{z}}}{\mathrm{dt}}=\mathrm{k}_{2} \mathrm{~b} \mathrm{E}_{\mathrm{oz}}
\end{gathered}
$$

141 where $\mathrm{k}_{1}$ and $\mathrm{k}_{2}\left[{ }^{\circ} \mathrm{Cd}^{-1}\right]$ are the individual relative elongation rate (RER) of the $\mathrm{DZ}$ and EOZ, 142 respectively, regardless of transition rate. The latter is given by $a$ and $b$ [dimensionless], representing 143 the relative rate of cell differentiation from $\mathrm{DZ}$ to $\mathrm{EOZ}$, and from EOZ to $\mathrm{MZ}$, respectively, proportional to the RER (e.g., at $a=1$ the absolute transition rate is equal to the RER of the DZ (i.e. $\left.k_{1}\right)$ ). In an 
extension of this model by Fournier et al. (2005), these proportional transition rates were made dependent on thermal time by:

$$
\begin{gathered}
t<t_{a}, a=0 \\
t \geq t_{a}, a=a_{d z}\left(t-t_{a}\right) \\
t<t_{b}, b=0 \\
t \geq t_{b}, b=b_{\text {eoz }}\left(t-t_{b}\right)
\end{gathered}
$$

148

Equation 2 uses a total of four parameters to describe the evolution of leaf zones, where $t_{a}$ and $t_{b}$ $\left[{ }^{\circ} \mathrm{Cd}\right]$ relate to the timing of initial cell transformation, i.e. from $D_{z}$ to $E_{o z}$, and from $E_{o z}$ to $M_{z}$, respectively. Parameters $a_{\mathrm{dz}}$ and $\mathrm{b}_{\mathrm{eoz}}\left[{ }^{\circ} \mathrm{Cd}^{-1}\right]$ relate to the rate at which the proportional cell transformation rate increases with thermal time in the respective zones.

\section{TURGOR-DRIVEN ELONGATION RATES}

To introduce elongation dependent on water limitations, the Lockhart (1965) equation, including the elastic portion introduced by Ortega (1985), was applied to replace the parametric growth rates $\mathrm{k}_{1}$ and $\mathrm{k}_{2}$ :

$$
\frac{1 \mathrm{dl}_{\text {zone }}}{\mathrm{l}_{\text {zone }} \mathrm{dt}}=\frac{1 \mathrm{~d} \psi_{\mathrm{p}}}{\varepsilon_{\text {zone }} \mathrm{dt}}+\phi_{\text {zone }}\left(\max \left(\psi_{\mathrm{p}}, \Gamma\right)-\Gamma\right)
$$

where the elongation rate of each zone $\left(\mathrm{dl}_{\text {zone }} \mathrm{dt}^{-1}\left[\mathrm{~m} \mathrm{~h}^{-1}\right]\right)$ depends on the cell wall properties of each zone (i.e. the elasticity $\varepsilon_{\text {zone }}[\mathrm{MPa}]$ and the extensibility $\phi_{\text {zone }}\left[\mathrm{MPa}^{-1} \mathrm{~h}^{-1}\right]$ ) as well as the turgor pressure $\left(\Psi_{\mathrm{p}}[\mathrm{MPa}]\right)$ and the threshold turgor $(\Gamma[\mathrm{MPa}])$, which is the minimal amount of turgor pressure required for irreversible yielding of the cell wall (i.e. actual growth). As the cellular structure between each zone is vastly different, the cell wall properties of each zone are also expected to differ significantly. In this study, we assumed fixed cell wall properties regardless of temperature or growth stage for model simplicity. However, inclusion of a temperature effect on the turgor-driven growth and transition rates is theoretically evaluated in more detail in a separate section below. Within the 
$D Z$, cell wall extensibility is non-zero, required for the creation of new cell layers. In the EOZ, cell wall extensibility is expected to be higher than in the other zones, due to the inherent elongating capabilities of these cells. The MZ contains only non-growing cells and is therefore considered to have a negligible extensibility (Lu \& Neumann 1998). Additionally, elasticity of the MZ can be 10-20 higher than the growing zones (Thomas, James \& Humphreys 1999). In the original model by Durand et al. (1999), only irreversible deformation was considered in the form of individual RER parameters per leaf zone (i.e. $k_{1}$ and $k_{2}$ ). Incorporation of the Ortega (1985) equation in the model adds these elastic changes (left-hand side of the equation), while incorporation of the Lockhart (1965) equation warrants

the replacement of these RER parameters by the turgor-driven growth concept:

$$
\begin{gathered}
\frac{1 \mathrm{~d} \psi_{\mathrm{p}}}{\varepsilon_{\mathrm{D}_{\mathrm{z}}} \mathrm{dt}}+\mathrm{k}_{1}=\frac{1 \mathrm{~d} \Psi_{\mathrm{p}}}{\varepsilon_{\mathrm{D}_{\mathrm{z}}} \mathrm{dt}}+\phi_{\mathrm{D}_{\mathrm{z}}}\left(\max \left(\psi_{\mathrm{p}}, \Gamma\right)-\Gamma\right) \\
\frac{1 \mathrm{~d} \Psi_{\mathrm{p}}}{\varepsilon_{\mathrm{E}_{\mathrm{oz}}} \mathrm{dt}}+\mathrm{k}_{2}=\frac{1 \mathrm{~d} \Psi_{\mathrm{p}}}{\varepsilon_{\mathrm{E}_{\mathrm{oz}}} \mathrm{dt}}+\phi_{\mathrm{E}_{\mathrm{oz}}}\left(\max \left(\psi_{\mathrm{p}}, \Gamma\right)-\Gamma\right) \\
\frac{1 \mathrm{~d} \Psi_{\mathrm{p}}}{\varepsilon_{\mathrm{M}_{\mathrm{z}}} \mathrm{dt}}=\frac{1 \mathrm{~d} \psi_{\mathrm{p}}}{\varepsilon_{\mathrm{M}_{\mathrm{z}}} \mathrm{dt}}
\end{gathered}
$$

whereby $k_{1}$ and $k_{2}$ are expressed in normal time $\left[h^{-1}\right]$. Notably, this equation introduces the elastic properties of the mature zone without the capability of growth. Thus, the turgor-driven elongation rate of each zone can be given as:

$$
\frac{\mathrm{dD}_{\mathrm{z}}}{\mathrm{dt}}=\mathrm{D}_{\mathrm{z}}\left(\frac{1 \mathrm{~d} \psi_{\mathrm{p}}}{\varepsilon_{\mathrm{D}_{\mathrm{z}}} \mathrm{dt}}+(1-\mathrm{a})\left(\phi_{\mathrm{D}_{\mathrm{z}}}\left(\max \left(\psi_{\mathrm{p}}, \Gamma\right)-\Gamma\right)\right)\right)
$$

$$
\begin{gathered}
\frac{\mathrm{dE}_{\mathrm{oz}}}{\mathrm{dt}}=\mathrm{a} \mathrm{D}_{\mathrm{z}} \phi_{\mathrm{D}_{\mathrm{z}}}\left(\max \left(\psi_{\mathrm{p}}, \Gamma\right)-\Gamma\right)+\mathrm{E}_{\mathrm{oz}}\left(\frac{1 \mathrm{~d} \psi_{\mathrm{p}}}{\varepsilon_{\mathrm{E}_{\mathrm{oz}}} \mathrm{dt}}+(1-\mathrm{b})\left(\phi_{\mathrm{E}_{\mathrm{oz}}}\left(\max \left(\psi_{\mathrm{p}}, \Gamma\right)-\Gamma\right)\right)\right) \\
\frac{\mathrm{dM}_{\mathrm{z}}}{\mathrm{dt}}=\mathrm{b} \mathrm{E_{ \textrm {oz } }} \phi_{\mathrm{E}_{\mathrm{oz}}}\left(\max \left(\psi_{\mathrm{p}}, \Gamma\right)-\Gamma\right)+\mathrm{M}_{\mathrm{z}} \frac{1 \mathrm{~d} \psi_{\mathrm{p}}}{\varepsilon_{\mathrm{M}_{\mathrm{z}}} \mathrm{dt}}
\end{gathered}
$$

As we focus solely on leaf elongation here, we assume a 1-dimensional model for simplicity. The straightforward extension of the model to 3D, which is relevant for applications such as functionalstructural plant modelling, whereby total leaf area plays a prominent role, are given in Supplementary 
Material S1. In a 1D elongation model, the total change in leaf volume is governed entirely by the increase in leaf length:

$$
\frac{1 \mathrm{dV}}{\mathrm{Vdt}}=\frac{1 \mathrm{dl}}{\mathrm{ldt}}
$$

Or:

$$
\frac{1 d V}{V d t}=\frac{1}{D_{z}+E_{o z}+M_{z}}\left(\frac{d D_{z}}{d t}+\frac{d E_{o z}}{d t}+\frac{d M_{z}}{d t}\right)
$$

The total volume of the leaf is determined by:

$$
V=\left(D_{z}+E_{o z}+M_{z}\right) w t_{h k} f_{\text {shape }}
$$

with $\mathrm{w}$ and $t_{h k}[\mathrm{~m}]$ representing the (constant) leaf width and thickness. $\mathrm{f}_{\text {shape }}$ [dimensionless] is a factor representing the fractional leaf area when compared to a rectangle with the same length / width ratio:

$$
f_{\text {shape }}=\frac{A_{\text {leaf }}}{\left(D_{z}+E_{\text {oz }}+M_{z}\right) w}
$$

where $A_{\text {leaf }}\left[\mathrm{m}^{2}\right]$ is the actual leaf area.

The result of applying the Lockhart (1965) equation as a replacement of the parametric growth rates (Eq. 4) is that leaf volume and leaf turgor pressure are now mutually connected. An increase in leaf turgor (above the threshold) increases the growth rate and subsequently relaxes leaf turgor. If turgor remains at, or below, the threshold, no growth occurs. The variations in leaf turgor that are observable throughout a day and consequently make leaf growth possible, are driven by the flow of water. Leaf water loss due to transpiration results in a decrease in turgor pressure, whereas water inflow due to plant water transport results in an increase in turgor pressure. The inflow of water also causes a change in leaf volume:

$$
\frac{d W}{d t}=\rho_{w} \frac{d V}{d t}
$$


204

205

206

207

208

209

210

211

$\frac{\mathrm{d} \psi_{\mathrm{p}}}{\mathrm{dt}}$

$$
=\left[\frac{1}{\left(D_{z}+E_{o z}+M_{z}\right) w t_{h k} f_{\text {shape }} \rho_{w} d t}-\left(\frac{D_{z} \phi_{D_{z}}+E_{o z} \phi_{E_{o z}}}{D_{z}+E_{o z}+M_{z}}\right)\left(\max \left(\psi_{p}, \Gamma\right)-\Gamma\right)\right] *
$$

$$
\left(\frac{\mathrm{D}_{\mathrm{z}} \frac{1}{\varepsilon_{\mathrm{D}_{\mathrm{z}}}}+\mathrm{E}_{\mathrm{oz}} \frac{1}{\varepsilon_{\mathrm{E}_{\mathrm{oz}}}}+\mathrm{M}_{\mathrm{z}} \frac{1}{\varepsilon_{\mathrm{M}_{\mathrm{z}}}}}{\mathrm{D}_{\mathrm{z}}+\mathrm{E}_{\mathrm{oz}}+\mathrm{M}_{\mathrm{z}}}\right)^{-1}
$$

or, when introducing $\mathrm{f}_{\mathrm{D}_{\mathrm{z}}}, \mathrm{f}_{\mathrm{E}_{\mathrm{oz}}}$, and $\mathrm{f}_{\mathrm{M}_{\mathrm{z}}}$ [dimensionless], which dynamically represent the fraction of the leaf currently in the $\mathrm{DZ}, \mathrm{EOZ}$, or $\mathrm{MZ}$, respectively:

$$
\frac{\mathrm{d} \psi_{\mathrm{p}}}{\mathrm{dt}}=\left[\frac{1}{\mathrm{l} w \mathrm{t}_{\mathrm{hk}} \mathrm{f}_{\text {shape }} \rho_{\mathrm{w}} \mathrm{dt}}-\left(\mathrm{f}_{\mathrm{D}_{\mathrm{z}}} \phi_{\mathrm{D}_{\mathrm{z}}}+\mathrm{f}_{\mathrm{E}_{\mathrm{oz}}} \phi_{\mathrm{E}_{\mathrm{oz}}}\right)\left(\max \left(\psi_{\mathrm{p}}, \Gamma\right)-\Gamma\right)\right] *\left(\mathrm{f}_{\mathrm{D}_{\mathrm{z}}} \frac{1}{\varepsilon_{\mathrm{D}_{\mathrm{z}}}}+\mathrm{f}_{\mathrm{E}_{\mathrm{oz}}} \frac{1}{\varepsilon_{\mathrm{E}_{\mathrm{oz}}}}+\mathrm{f}_{\mathrm{M}_{\mathrm{z}}} \frac{1}{\varepsilon_{\mathrm{M}_{\mathrm{z}}}}\right)^{-1}
$$

This equation can then be used to calculate the change in different tissue zones from Eq. 5 .

Both growth rates and transition rates were assumed linearly related to thermal time in the original 
turgor-driven growth results in a dependency of growth rates of each leaf zone on the established turgor pressure within the leaf, but leaves transition rates unaffected. A dependency of the progression of $\mathrm{a}$ and $\mathrm{b}$ on turgor conditions is therefore warranted. We propose the introduction of $\mathrm{a}$ new concept called "turgor-time" ( $\left.\mathrm{t}_{\mathrm{p}}^{\psi_{\mathrm{p}}}[\mathrm{MPa} \mathrm{h}]\right)$ to model these transition rate variables.

Whereas thermal time is calculated as the difference in average temperature and crop base temperature, turgor-time is similarly calculated, using the difference between current turgor pressure and the lowest turgor-pressure to enable growth (i.e. the turgor threshold, $\Gamma$ ). One physical hour $(\mathrm{t}[\mathrm{h}]$ ) can therefore be transformed into turgor hours by:

$$
\mathrm{t}^{\psi_{\mathrm{p}}}=\mathrm{t}\left(\max \left(\Psi_{\mathrm{p}}, \Gamma\right)-\Gamma\right)
$$

Introducing this concept into Eq. 2 results in a dependency of the transition rate progression on turgor pressure:

$$
\begin{gathered}
\mathrm{t}^{\psi_{\mathrm{p}}}<\mathrm{t}_{\mathrm{a}}^{\psi_{\mathrm{p}}}, \mathrm{a}=0 \\
\mathrm{t}^{\psi_{\mathrm{p}}} \geq \mathrm{t}_{\mathrm{a}}^{\psi_{\mathrm{p}}}, \mathrm{a}=\mathrm{a}_{\mathrm{dz}}^{\psi_{\mathrm{p}}}\left(\mathrm{t}^{\psi_{\mathrm{p}}}-\mathrm{t}_{\mathrm{a}}^{\psi_{\mathrm{p}}}\right) \\
\mathrm{t}^{\psi_{\mathrm{p}}}<\mathrm{t}_{\mathrm{b}}^{\psi_{\mathrm{p}}}, \mathrm{b}=0 \\
\mathrm{t}^{\psi_{\mathrm{p}}} \geq \mathrm{t}_{\mathrm{b}}^{\psi_{\mathrm{p}}}, \mathrm{b}=\mathrm{b}_{\mathrm{eoz}}^{\psi_{\mathrm{p}}}\left(\mathrm{t}^{\psi_{\mathrm{p}}}-\mathrm{t}_{\mathrm{b}}^{\psi_{\mathrm{p}}}\right)
\end{gathered}
$$

where $\mathrm{t}_{\mathrm{a}}^{\psi_{\mathrm{p}}}$ and $\mathrm{t}_{\mathrm{b}}^{\psi_{\mathrm{p}}}[\mathrm{MPa} \mathrm{h}]$ represent the turgor-based timing of cell transformation initiation. $\mathrm{a}_{\mathrm{dz}}^{\psi_{\mathrm{p}}}$ and $\mathrm{b}_{\mathrm{eoz}}^{\psi_{\mathrm{p}}}\left[\mathrm{MPa}^{-1} \mathrm{~h}^{-1}\right]$ determine the rate at which the transition increases with turgor-time. This definition of turgor-time means that essentially both the growth and transition rates within this model are linearly expressed in terms of turgor-time.

Whereas the expression of growth in terms of thermal time has the advantage of having a uniform expression in terms of temperature treatments, the concept of turgor-time attempts to do the same for treatments of water availability. However, a dependency on temperature must be included in the Lockhart (1965) equation to capture the effects on growth of both temperature and turgor within the turgor-time concept. Temperature can have a variety of effects on the growth parameters used in our model (see discussion section). For simplicity, we use the inverse temperature/threshold turgor 
relation established in Proseus et al. (2000) in an example to evaluate the relation between growth expressed in thermal time versus turgor-time when temperature dependencies are included in the turgor-driven growth model. Proseus et al. (2000) quantified this relation between temperature, turgor and growth by using large-celled algae as a model for plant growth and found that under reestablished turgor (i.e. compensating for the osmotic effect of temperature) at low temperatures, growth did not resume unless turgor was raised above the original value. Raising turgor pressure under these reduced temperatures was able to almost completely compensate for the temperatureinduced growth reduction. As a result, a linear temperature-dependency of threshold turgor could compensate, for a large part, the temperature effect on growth. In theory, this assumption would allow the turgor-time concept to capture the effects of both drought stress and temperature within a single growth curve (Fig. 1). In order to test this hypothesis, the relationship between growth rate expressed in thermal time as opposed to turgor-time was investigated under different temperature dependencies of the threshold turgor and differences in prevailing turgor pressure within the growing zone. However, this temperature dependency was not included in the case study as there was no difference in temperature treatments within the data.

Modelling realistic daily fluctuations in turgor pressure in a solitary leaf requires basic assumptions regarding the regulating factors for establishing turgor pressure in the cells. This includes the water loss due to transpiration, the daily fluctuations of sheath/stem water potential due to transpirational water loss of previously established leaves and the osmotic pressure within the developing leaf. In an effort to showcase the model dynamics, rather than the underlying drivers of turgor pressure, a conscious decision was made to model these assumptions in the simplest manner that maintains a basic level of realism. 
Firstly, the transpiration rate of the developing leaf (i.e. the modelled leaf) was modelled as a fixed pattern, the magnitude of which increases with respect to the growing leaf area:

$$
E_{\text {leaf }}=E^{\text {scale }} \max \left(0, \frac{\sin \left(\frac{(t-8) \pi}{12}\right)+0.5}{1.5}\right) A_{\text {leaf }}
$$

This function models leaf transpiration $\left(E_{\text {leaf }}\left[\mathrm{g} \mathrm{h}^{-1}\right]\right.$ ) as a strictly positive sine function, representing a day length of 16 hours with sunrise at $6 \mathrm{AM}$ and sunset at $22 \mathrm{PM}$, corresponding to the treatment applied to the kinematic dataset (see below). A scale parameter ( $E^{\text {scale }}\left[\mathrm{g} \mathrm{h}^{-1} \mathrm{~m}^{-2}\right]$ ) was used which represents the peak transpiration rate which depends on the overall leaf area $\left(\mathrm{A}_{\text {leaf }}\left[\mathrm{m}^{2}\right]\right)$. In reality, transpiration rates may also be dependent on leaf or plant age, which was not considered in this approach.

Transpiration rates of the previously established leaves $\left(\mathrm{E}_{\text {canopy }}\left[\mathrm{g} \mathrm{h}^{-1}\right]\right)$ were modelled similarly, but their increase in leaf area was considered negligible. Thus, a fixed scale parameter $\left(\mathrm{A}_{\text {canopy }}\left[\mathrm{m}^{2}\right]\right)$ represents the magnitude of water loss of the canopy during the day.

$$
E_{\text {canopy }}=E^{\text {scale }} \max \left(0, \frac{\sin \left(\frac{(t-8) \pi}{12}\right)+0.5}{1.5}\right) A_{\text {canopy }}
$$

The water loss within the developing leaf will directly impact the leaf turgor pressure due to the loss in water content (Eq. 12). For the whole canopy a more simplified approach is taken, where the loss of water impacts the canopy water potential $\left(\psi_{\mathrm{w}, \text { canopy }}[\mathrm{MPa}]\right)$ based on the whole canopy water content $\left(\mathrm{W}_{\text {canopy }}[\mathrm{g}]\right)$ and the canopy hydraulic capacitance $\left(\mathrm{C}_{\text {canopy }}\left[\mathrm{g} \mathrm{MPa}^{-1}\right]\right)$ :

$$
\Psi_{\mathrm{w}, \text { canopy }}=\frac{\mathrm{W}_{\text {canopy }}-\mathrm{W}_{\text {canopy }}^{\max }}{\mathrm{C}_{\text {canopy }}}
$$
potential ( $\left.\psi_{\mathrm{w}, \text { stem }}[\mathrm{MPa}]\right)$ can be modelled: 


$$
\psi_{\mathrm{w}, \text { stem }}=\frac{\mathrm{W}_{\text {stem }}-\mathrm{W}_{\text {stem }}^{\mathrm{max}}}{\mathrm{C}_{\text {stem }}}
$$

based on the stem hydraulic capacitance $\left(\mathrm{C}_{\text {stem }}\left[\mathrm{g} \mathrm{MPa}^{-1}\right]\right)$ and the difference between current ( $\left.\mathrm{R}_{\text {stem } \rightarrow \text { leaf }}^{\mathrm{X}}\left[\mathrm{MPa} \mathrm{h} \mathrm{g}^{-1}\right]\right):$

$$
\begin{aligned}
\mathrm{F}_{\text {stem }} & =\frac{\psi_{\text {soil }}-\psi_{\text {stem }}}{\mathrm{R}_{\text {soil } \rightarrow \text { stem }}^{\mathrm{X}}} \\
\mathrm{F}_{\text {canopy }} & =\frac{\psi_{\text {stem }}-\Psi_{\text {canopy }}}{\mathrm{R}_{\text {stem } \rightarrow \text { canopy }}^{\mathrm{X}}} \\
\mathrm{F}_{\text {leaf }} & =\frac{\psi_{\text {stem }}-\psi_{\text {leaf }}}{\mathrm{R}_{\text {stem } \rightarrow \text { leaf }}^{\mathrm{X}}}
\end{aligned}
$$

As a result, both soil water potential $\left(\psi_{\text {soil }}[\mathrm{MPa}]\right)$ and transpiration rates will be the main determinants of water availability during leaf growth.

Leaf water potential is determined by both turgor and osmotic components:

$$
\psi_{\text {leaf }}=\psi_{\mathrm{p}}+\psi_{\mathrm{o}}
$$
$\left[\mathrm{mol} \mathrm{m}^{-3}\right]$ ) within the leaf according to the van ' $\mathrm{t}$ Hoff equation:

$$
\psi_{\mathrm{o}}=-\mathrm{RTC}_{\text {sugar }}
$$

The soluble sugar concentration is where photo-assimilate availability (through photosynthesis) will impact leaf growth within the turgor-driven growth concept, with lower availability resulting in a less negative osmotic potential (Coussement, De Swaef, Lootens \& Steppe 2020). This will, in turn, lower 
the growing leaf's ability to generate a high turgor pressure required for growth. However, soluble sugar concentration is difficult to consider for an isolated leaf, as the whole-plant interactions play an important role in the overall production, conversion, and transport priorities of accumulated carbohydrates. Therefore, a fixed osmotic potential, directly linked to soil water availability was assumed. The rationale behind this decision is that with such an approach the entire model dynamics are caused by plant-water relations. Alternative patterns for the osmotic potential were also explored, namely a fixed diurnal patterns and an increasing diurnal pattern with leaf development to better understand the role of the osmotic potential within the model. The link to soil water potential $\left(\psi_{\mathrm{s}}\right.$; $\mathrm{MPa}$ ) was included because leaves are capable of osmotic adjustment under drought stress (e.g., in barley (Matsuda and Riazi 1981), wheat (Munns \& Weir 1981), maize (Michelena and Boyer 1982; Westgate and Boyer 1985)). As a result, the following function was used:

where leaf osmotic potential $\left(\psi_{\mathrm{o}, \text { leaf }}[\mathrm{MPa}]\right)$ is directly linked to a baseline osmotic potential under well-watered conditions $\left(\psi_{0, \text { leaf }}^{\mathrm{WW}}[\mathrm{MPa}]\right)$ with a linear capacity for osmotic adjustment ( c [dimensionless]) based on soil water availability.

\subsection{MODEL CALIBRATION, IMPLEMENTATION, SENSITIVITY, AND SIMULATION}

\section{MODEL CALIBRATION USING A MAIZE KINEMATIC EXPERIMENT}

The model was developed to present a general framework to assess grass leaf growth under both wellwatered and drought conditions. Besides a theoretical verification of the model with literature reported observations, a case study was conducted for maize using experimental data to obtain 
realistic parameter values and validation results. To this end, data from the kinematic experiment from Nelissen et al. (2018) was used. Within this experiment length of the entire leaf and of the division zone (DZ) were measured under control and mild drought treatments for the fourth leaf of maize plants (V3 stage). For the mild drought treatment, water content was allowed to drop to a soil water content of $70 \%$ of the well-watered treatment, corresponding to a soil water potential of -0.52 $\mathrm{MPa}$, and $-0.02 \mathrm{MPa}$, respectively. The plants were grown under growth chamber conditions (VIB, $51.0180^{\circ} \mathrm{N}, 3.6941^{\circ} \mathrm{E}$ ) with a 16 -hour light period from $6 \mathrm{AM}$ to $22 \mathrm{PM}$. Light period temperature was set to $26^{\circ} \mathrm{C}$ and $22{ }^{\circ} \mathrm{C}$ for the dark period. Water supply was automated to ensure equal conditions between the plant within each treatment. The mild drought treatment was obtained by a linear reduction in soil water content starting at the time of sowing before reaching the final $\psi_{\mathrm{s}}$ of $-0.52 \mathrm{MPa}$ after 6 days. The fourth leaf emerged 7 days after sowing, and it was assumed that the leaf is initiated 4 days prior. Thus, a linear decrease in $\psi_{\mathrm{s}}$ from $-60 \mathrm{~h}$ to +84 hours was included in the model. The crop base temperature (which only serves for the conversion of simulation results to thermal time) was assumed $0^{\circ} \mathrm{C}$, to coincide with 24 degree days in a single day. The data from both treatments were simultaneously used to calibrate the model, obtaining estimates for the ontogeny parameters $\left(a_{\mathrm{dz}}^{\Psi_{\mathrm{p}}}\right.$ resistances within the system and the osmotic compensation factor c. A fixed value of -0.6 MPa for $\psi_{0, \text { leaf }}^{\mathrm{wW}}$ was assumed (Tang \& Boyer 2002).

During this experiment, no measurements of whole-plant transpiration, sap flow, or water potential components were conducted. Daily monitoring in the kinematic experiment excluded the possibility for observing diurnal trends. An estimate for leaf transpiration rate and overall canopy leaf area at the V3 stage was obtained from a second experiment, which was conducted on the same genotype under slightly different conditions in the greenhouse at VIB. The plants were grown on a high-throughput phenotyping system with automated watering. All plants were photographed daily from six side angles and one top view to facilitate 3D reconstruction. This allowed extraction of total leaf area at the V3 
stage of the plants. These data were combined with gas exchange measurements, conducted using a portable photosynthesis system (model LI- 6400XT, Li-Cor Inc., Licoln, Nebraska, USA) to determine a realistic estimate of $\mathrm{E}_{\text {leaf }}$ and thus also $\mathrm{E}_{\text {canopy, }}$ and six additional parameters $\left(\mathrm{W}_{\text {stem }}^{\max }, \mathrm{W}_{\text {canopy }}^{\max }, \mathrm{C}_{\text {stem }}\right.$, $\mathrm{C}_{\text {canopy }}, \mathrm{R}_{\text {soil } \rightarrow \text { stem }}^{\mathrm{X}}$, and $\mathrm{R}_{\text {stem } \rightarrow \text { canopy }}^{\mathrm{X}}$ ) to realistically describe the patterns relating to a stage $\mathrm{V} 3$ plant.

The model was implemented in Rstudio (R version 3.5.3; R Core Team 2016). The system of differential equations was bundled in a single function for use with the package deSolve (Soetaert et al. 2010a; Soetaert et al. 2010b) which has access to a variety of solvers. The model was solved using the "vode" solver (Brown, Byrne \& Hindmarsh 1989) which can be accessed through this package, chosen for its capability of solving stiff systems. Even though the model, applied to a solitary leaf, is not an inherently difficult problem to solve, the stiff nature of the dynamic system of water transport equations applied to a more complex structure can lead to drastically increased computation times if the appropriate solver is not chosen (e.g., Nikinmaa et al. 2014; Coussement et al. 2018).

Model calibration was done using the DZ and total leaf length data, as well as the derived leaf elongation rate, from the kinematic experiment under control conditions. The goal function was defined as the product of the mean sum of squares of both datasets at the corresponding simulation times.

Model sensitivity was evaluated using relative sensitivity functions $S\left(y_{i}\right)$, whereby the sensitivity of each parameter $(\theta)$ was evaluated by comparing the effect on simulated leaf length $\left(y_{i}\right)$, when the parameter is varied $1 \%(\Delta)$ around their optimised value (Steppe, De Pauw, Lemeur \& Vanrolleghem 2006):

$$
S\left(y_{i}\right)=\frac{y_{i}(\theta+\Delta \theta)-y_{i}(\theta-\Delta \theta)}{2 y_{i}(\theta)} 100
$$


Ranking of relative sensitivity curves facilitated ordering the parameter set based on relative influence on overall leaf length development. Visual comparison of the sensitivity curves facilitated assessment of collinearity. Collinearity (De Pauw, Steppe \& De Baets 2008) between a pair of parameter sensitivity curves is an indication that a change in one parameter value can be compensated by a change in another, leading to a pair of parameters which cannot be simultaneously estimated. As a result, at least one of these parameters will need to be assumed fixed, based on their relative sensitivity or parameter stability. In order to facilitate interpretation of these curves, each curve was summarized into an index (i.e., average, absolute sensitivity value) for each distinct growing phase of the leaf: early growth stage $\left(0-125^{\circ} \mathrm{Cd}\right)$, linear growth stage $\left(125-300^{\circ} \mathrm{Cd}\right)$, maturation stage $\left(300-600^{\circ} \mathrm{Cd}\right)$. This process was repeated for the two measured scenarios (i.e., control conditions at $\psi_{\mathrm{s}}-0.02 \mathrm{MPa}$ and mild drought stress at $\psi_{\mathrm{s}}-0.52 \mathrm{MPa}$ ) as well as a theoretical severe drought scenario whereby $\psi_{\mathrm{s}}$ was $-1.5 \mathrm{MPa}$.

\section{MODEL PERFORMANCE UNDER DROUGHT STRESS CONDITIONS}

Aside from evaluating the goodness of fit of the model in both measured treatments, theoretical model scenarios on water deficit were conducted and compared with reported observations on drought stress on leaf elongation rate: i) a stronger reduction in soil water potential; ii) an increase in transpiration rate; iii) a reduction in soil water potential with lower transpiration rates (representing the effect of stomatal closure); iv) drought stress (soil) with early and late rewatering. In all these scenarios, soil water potential was gradually decreased during the first few days of the simulation, similar to the experimental setups. 
Model simulations of grass leaf elongation with calibrated parameters under well-watered conditions

(Table 1) were in line with simulation patterns of the original model by Durand et al. (1999), and additionally showed the patterns of contraction and expansion (Fig. 2). These patterns are the result of changes in turgor during the day, triggered by diurnal cycles of water loss due to transpiration. The turgor-driven leaf elongation model was able to adequately describe the measured patterns of leaf length under well-watered and drought conditions (Fig. 2A; B). Simulations of DZ length are slightly skewed compared to the measured patterns (Fig. 2C; D). The pattern of leaf elongation rate (Fig. 2E; F) shows a rather stable period of elongation corresponding to the period of linear growth after which a steep decline occurs. With the same model parameters but a lower soil water potential $\left(\psi_{\mathrm{s}}\right.$ from 0.02 to $-0.52 \mathrm{MPa}$ ), the model simulated a slight reduction in elongation rate with an increase in leaf elongation duration (LED), which closely corresponded to the measured data (Fig. 2B; D; F). Overall, final leaf length was shorter as the slower elongation rate was not fully compensated by the increase in LED. DZ length was similarly lower, with a slower transition to EOZ.

ELONGATION RATE AND DURATION APPEAR TO BE INVERSELY RELATED, GOVERNED BY THE TRANSITION RATE

A full list of model parameter and input sensitivity indices per growth stage and drought treatment in terms of final leaf length is given in Supplementary Material S3. The general sensitivity of the model towards each parameter or input increased with increasing drought stress. This trend is especially strong with model sensitivity towards the soil water potential and the osmotic compensation factor. Rather unexpectedly, model sensitivity is generally highest during the division and elongation stages of the growth, with the relative importance of the elongation phase increasing with incremental drought stress. A noticeable exception to this rule is the influence of the transition parameter from the EOZ to the $M Z\left(b_{\text {eoz }}\right)$ of which the maximal influence coincides with the maturation stage. $b_{\text {eoz }}$ is 
negatively correlated to final leaf length, as a higher transition rate results in a faster maturity and thus a reduction in LED.

The highest model sensitivity, regardless of drought treatment, could be found in the soluble sugar concentration where relative leaf elongation rates are highest. Other notably sensitive parameters include the zone extensibilities and the threshold turgor. A collinearity existed between the threshold turgor and the soluble sugar concentration because both direct the magnitude of the established turgor at any time in the simulation, with no changes across leaf development stage. The impact of transition from DZ to EOZ $\left(a_{d z}\right)$ was relatively small, but interestingly showed a positive sensitivity in early growth stages and a negative sensitivity in the later growth stages, indicating that a higher transition rate between $\mathrm{DZ}$ and EOZ can lead to a rapid burst of elongation but at the expense of LED. The sensitivities of the elasticity components in each zone were a factor 10-20 lower than the extensibilities. Even so, the elasticities in the DZ especially, and in the EOZ to a lesser extent, had a lasting positive effect on the final leaf length. Sensitivities of stem or canopy capacitance were very limited, possibly because our simplified assumptions of water flow and storage in the plant do not include negative feedbacks (e.g., increased resistance or stomatal closure) of decreased water supply in these organs. Instead, these effects are captured in the more sensitive parameters for leaf and canopy transpiration, organ water content, and overall transport resistance. Leaf elongation rate is more sensitive to the transpiration rate of the established canopy than that of the growing leaf especially in the early growth stages.

A more negative soil water potential $\left(\psi_{\mathrm{s}}\right)$ resulted in a stronger inhibiting effect on leaf growth and a stimulating effect on LED (Fig. 3A). When $\psi_{\mathrm{s}}$ becomes too negative, so that the osmotic compensation effect (Eq. 22) can no longer raise turgor above the threshold, growth completely halts (data not shown). A theoretical drought scenario where $\psi_{\mathrm{s}}$ was reduced from -0.02 to $-0.52 \mathrm{MPa}$ between -60 

and $84{ }^{\circ} \mathrm{Cd}$ (as in the experiment) with an early rewatering $\left(\psi_{\mathrm{s}}\right.$ recovery to $-0.02 \mathrm{MPa}$ between 84 and $447150^{\circ} \mathrm{Cd}$ ) showed a gradual inhibition in LERs upon application of drought but a rapid recovery of LERs and thus barely increased LED (Fig. 3B). Later rewatering, namely after peak elongation phase ( $\psi_{\mathrm{s}}$ recovery to $-0.02 \mathrm{MPa}$ between 350 and $450^{\circ} \mathrm{Cd}$ ), still resulted in a small restoration of LERs but LED is significantly increased (Fig. 3B). The magnitude of transpiration rates affects LER in a similar way as soil water deficit (Fig. 3C), whereby an increase in transpiration rate results in water deficit and thus a drought stress response on LER and LED, and vice versa. However, contrasting to soil water deficit, this effect results in increased differences between light and dark period elongation rates, as transpiration rate primarily affects light period water availability. Under realistic drought conditions, whereby stomatal closure regulates the plant's water loss due to transpiration, the effect of a low $\psi_{\mathrm{s}}$ on LER is slightly alleviated with a lower transpiration rate, as the light period LER is less severely inhibited (Fig. 3D). DROUGHT TREATMENTS

Decreasing $\psi_{\mathrm{s}}$ resulted in a reduction in simulated length of each leaf zone (Fig. 4). When expressed in terms of thermal time, the effect of decreased $\Psi_{s}$ on LED results in a different elongation pattern for various drought treatments (Fig. 4A; C; E) as the drought stress effect on LER and LED does not impact perceived temperature for the plant. However, when expressed in terms of turgor-time, the growth patterns of each scenario are remarkably similar (Fig. 4B; D; F) as the perceived turgor-time is linearly related to the growth rate. This is the result of the slowdown in growth being captured by a smaller increase in leaf turgor age under stress, especially during daytime hours. As a result, the length of a single day under heavy drought stress has a severely reduced impact on the progression of leaf turgor age while leaf thermal age remains unaffected (Fig. 4B; D; F). 
470 If turgor-time were to function as a metric to normalise growth expression under different

471 temperature and drought regimes, growth simulations with the Lockhart equation under different

472 temperatures should result in identical growth rates when expressed in thermal time (i.e. a constant

473 LER per unit of thermal time). We observed that the integration of a linear dependency of threshold

474 turgor on temperature only resulted in constant LERs (expressed per thermal time unit) for specific combinations of parameters and temperature. The LER per unit thermal time was found to be dependent on the slope between threshold turgor and temperature, the value of threshold turgor itself, and the magnitude of prevailing turgor pressure. A visual representation of these results is given in Fig. 5, which shows the simulated LER per unit thermal time for various slope values and temperature treatments under stable turgor conditions (i.e., no change in turgor pressure due to diurnal variations). In this example, only one specific slope variable (i.e. $-0.01667 \mathrm{MPa}^{\circ} \mathrm{C}^{-1}$ ) was able to maintain a stable growth rate in terms of thermal time under the chosen conditions. Moreover, growth rate stability per thermal time was further dependent upon the prevailing turgor pressure (Fig. 6) even when the derived slope variable of $0.08 \mathrm{MPa}{ }^{\circ} \mathrm{C}^{-1}$ was used. This theoretical exercise showed that, in reality, a more complex relation than linear between turgor-driven growth and temperature is needed, possibly including an effect on extensibility as well (Pritchard, Wyn Jones et al. 1990; Cosgrove 2000; Pietruszka and Lewicka 2007), before turgor-time can be used as a uniform expression of growth and development across both temperature and drought treatments.

DIURNAL FLUCTUATIONS IN OSMOTIC POTENTIAL CAN LEAD TO TURGOR ACCUMULATION AND REVERSED SAP FLOW

As the sensitivity analysis showed that LER is highly sensitive to the osmotic potential, the validity and implications of our assumption of a stable osmotic potential was also investigated with two alternative diurnal osmotic patterns (Fig. 7). These patterns were based on the assumption that osmotic 

at sunset and consumption of solutes due to growth during the night causes a minimum at sunrise. In a first scenario, this fixed diurnal pattern is assumed constant over the course of leaf development (Fig. 7C). In a second scenario, it is assumed that the osmotic potential remains rather stable during the early growth phases, and the amplitude of these fluctuations increases with leaf development (i.e., the fraction of $M Z$ in the leaf) (Fig. 7E). Introducing either diurnal pattern in the simulations causes daily peaks in turgor pressure which coincide with the highest osmotic solute concentration (sunset). In the first scenario, where these daily turgor peaks are already present in the early growth stages, these peaks resulted in an acceleration of growth. However, in the later growth stages (in both scenarios), when the fraction of mature leaf increases and extensibility becomes low, these daily transpiration-driven contraction at sunrise (Fig. 7B).

TURGOR-DRIVEN GROWTH- AND TRANSITION SIMULATIONS CAPTURE LITERATURE REPORTED DROUGHT STRESS RESPONSES IN TERMS OF ELONGATION RATES, DURATION AND ZONE TRANSITION

Our model simulations under drought stress correspond with various literature-reported observations of LER under water deficit. Daytime depressions (but not a total growth halt) in leaf elongation rate

514 (Tardieu, Parent, Caldeira \& Welcker 2014), which are increased by mild water deficit (Parent, Suard, Serraj \& Tardieu 2010; Pantin, Simonneau, Rolland, Dauzat \& Muller 2011; Caldeira et al. 2014) are clearly visible in the model simulations (Fig. 2,3). Drought stress reduces the length of the growing zone (Durand et al. 1995), which results in a more basal position of DZ due to a significant reduction 
in DZ cell number and size (Nelissen et al. 2018), and also an increase in growth duration (Nelissen et al. 2018). Similarly, cell expansion rate severely reduces, but time spent in the elongation zone increases, whereas these adverse effects in DZ and EOZ are less pronounced in drought-tolerant species (Avramova et al. 2017). Fast rewatering under mild drought, before the peak of the elongation stage, is able to nearly completely restore drought-induced LER inhibition and therefore does not lead to an increase in LED (Fig. 3B). A decrease in VPD (and thus reduced leaf transpiration; Fig. 3C) can lead to a rapid increase in LER in both light and dark periods (Parrish \& Wolf 1983). In our model, this LER increase under lower VPD can be maintained for several days after emergence, which is in line with a detailed study on Arabidopsis (Pantin et al. 2011), however, due to a related decrease in LED, our model shows a faster leaf maturity (and thus reduced LERs) for which we found no previous reports. Transpiration rate also affects the magnitude of the difference between light and dark period LER, whereby higher transpiration has a stronger inhibiting effect on light period LER (Fig. 3C), as observed in stomatal mutants in Arabidopsis (Pantin et al. 2011).

In our model, we assume equal water status across each leaf zone. This is not a far-fetched assumption for the osmotic portion of the model, with a near-equal sink strength observed for the DZ and EOZ in tall-fescue (Allard \& Nelson, 1991). These leaves spend up to $80 \%$ of their elongating phase as net importers of assimilates (Brégard \& Allard 1999), so this assumption may hold for the bulk of leaf development, as later deviations will affect overall LER less than during initial development. Aside from the osmotic portion, the water status of the leaf is reported to be different in the MZ as opposed to the growing zones because the MZ has a high hydraulic capacitance while the EOZ has a lower capacitance (Caldeira et al. 2014). The result of this effect is that minimal transpiration can create a sharp decrease in LER (i.e. in the EOZ) which is able to recover fast, while overall leaf water potential is slower to respond (Caldeira et al. 2014). Tardieu et al. (2000) reports a more drastic inhibition of EOZ elongation rate than the DZ. This could occur due to a higher local transpiration rate, or a higher extensibility in the EOZ, both of which can lead to lower turgor. It would be possible to include these dynamics within the model by assuming a non-equal water status in the model, including lateral water 
544 flows within the leaf, and top-down streams from the stored water in the $\mathrm{MZ}$ to the elongating zones.

545 This comes at the cost of complicating the model and the solving process of the system and practical 546 application may be hindered by difficulties in capturing these fine-scale movements of water and 547 sugar loading within the different zones. While such an addition may be interesting for specifically studying the dynamics over time, we considered such level of detail excessive for studying the turgordriven growth dynamics of the whole-leaf scale. DROUGHT STRESS AND DURING LEAF INITIATION

Sensitivity analysis of the model revealed that the osmotic potential is one of the largest determinants of the elongation rates, especially in the early stages of leaf development. This is unsurprising, as the magnitude of leaf osmotic potential determines the magnitude of turgor-pressure in a hydraulic system with no growth. Although we modelled a constant osmotic potential, diurnal fluctuations in leaf osmotic potential may exist, depending on import and consumption of carbohydrates in dividing and elongating cell tissue, and production and export from the mature cell zones. Leaf soluble sugar content is reported to be minimal around sunrise and maximal around sunset (e.g., barley (Sicher et al. 1984); maize (Ning et al. 2018)), although peak times may differ depending on the developmental stage of the plant (e.g., wheat (Ning et al. 2018)). While data of these diurnal variations in the DZ and the EOZ are scarce, it is these fluctuations that are of primary importance for our modelling results, as they dictate turgor pressure within the zones that are enabling leaf elongation. The assumed equal water status across all leaf zones means that the diurnal patterns in osmotic and turgor pressure simulated in the entire leaf closely resemble those of the DZ and EOZ. However, evidence suggests that diurnal fluctuations in osmotic potential in the basal zone (in the range of $0.05 \mathrm{MPa}$ ) of a growing maize leaf are less pronounced than those in mature regions (in the range of $0.5 \mathrm{MPa}$ ) (Tang \& Boyer 
leaf hydraulics during the early growth stages play a minor role (Pantin et al. 2011). This active loading in the division and elongation zones could be the reason why inclusion of a gradual application of drought in the early division stage (rather than constant immediate drought) proved essential for realistic drought simulations (Figs. 2, 3, 4) with our model. Simulations with a full drought from leaf initiation heavily inhibited leaf growth unless the initial size of the DZ was increased which may imply active osmotic loading in these cells to be essential for leaf development under drought (Pantin et al. 2011). This is further supported by sensitivity analysis of the model, which revealed the osmotic potential to be the most influential factor in establishing early leaf growth, its influence only increasing as drought stress is applied (Supplementary material 3).

The effect of diurnal fluctuations in osmotic potential on the model simulations, both with a constant diurnal pattern, and an increasing amplitude with leaf development (Fig. 7) were separately investigated. Interestingly, simulations resulted in large increases in nighttime turgor in the $M Z$, as accumulation of soluble sugar caused water inflow with limited to no cell-wall yielding (i.e. no extensibility). This is in agreement with observations made in the mature zones of maize leaves, which are reported to generate higher turgor than elongating zones (Tang \& Boyer 2002; Bouchabké, Tardieu \& Simonneau 2006). Vice-versa, a drop in leaf water potential and turgor pressure has been reported in the growing zones of maize leaves (Tang \& Boyer 2002; Bouchabké et al. 2006), which corresponds to our modelling results in all osmotic scenarios, where relaxation of cell walls in the EOZ under favourable turgor results in a reduction in turgor pressure (Fig. 7). However, Bouchabké et al. (2006) state that within the EOZ, turgor pressure is highest in the cell areas with the largest RER, which indicates active loading of osmotic solutes to maintain turgor pressure within these cells. 
593 By keeping the osmotic potential constant, we ensured that diurnal fluctuations in the model 594 originated from hydraulics only. With a fixed soil water potential, transpiration rates cause the fluctuations in daytime elongation rates. The transpiration rate of the elongating leaf has limited effect at early growth stages, partly due to the limited leaf area. Also in reality, transpiration rate per leaf area will be lower at early growth stages, because the whorl of older leaves envelops a large portion of the developing leaf in grass species (Brégard \& Allard 1999). At the whole-plant level, transpiration also drives daily fluctuations in stem water potential, which strains the supply of water towards the elongating leaf. This approach allowed us to simulate theoretical effects of two different types of drought stress, being atmospheric and soil drought. This distinction is important because both drought types are reported to have an independent, near-additive effect on leaf elongation rate (Tardieu, Reymond, Hamard, Granier \& Muller 2000). Our simulations showed similar results, in which an increase in transpiration triggered a decrease in LER and increase in LED, while decreased transpiration results in the opposite effect (Fig. 3C). However, in our simulations, a change in transpiration was modelled as a solitary event, without any impact on the soluble sugar concentration (i.e. which might result from reduced photosynthesis under drought stress (Chaves, Maroco \& Pereira 2003)) within the leaf, which may have underestimated the overall effect. Still, clear reductions in LER during daytime hours were simulated across all leaf zones, corresponding to observations made in e.g. maize (Tardieu et al. 2000) and tall fescue (Schnyder \& Nelson 1988). This is in contrast to measurements made in Arabidopsis where RER at early growth stages shows an inverse pattern (and only under well-watered conditions), with higher RER during daylight (Pantin et al. 2011). Under specific conditions, this inverse pattern can also occur in monocots, whereby an increase in sugar loading in the growing leaf during daylight hours can lead to a lower osmotic potential and thus higher turgor pressure and RER. Additionally, under field conditions, nighttime RER can be negatively affected by drastically lower nighttime temperatures which can also contribute to this inverse pattern (Acevedo, Fereres, Hsiao \& Henderson 1979; Tardieu et al. 2000). 
The introduced concept of turgor-time has the potential to become a new metric to merge the effects of temperature, sugar, and water availability in a single, normalised growth curve. The growth pattern of a plant or a plant organ is currently often expressed in terms of a sigmoid curve (e.g., Yin et al. 2003), which is parameterised by functional variables related to the timing of the growth pattern (i.e. one parameter representing the thermal time at which growth has reached its halfway point and growth rate is maximal, and one parameter representing the thermal time at which growth has completed) and the final size of the plant (resp. organ). As these timing parameters are expressed in thermal time, these sigmoid curves have the strength to be applicable in treatments of varying temperature (Fig. 1 B4; C4). Our model simulations have shown turgor-time to have the same strength for various drought treatments (Fig. 4), whereby the parameters related to the timing of the growth curve are unchanged, regardless of drought treatment, when expressed in turgor-time. The practical use of the concept of turgor-time may be hindered by the difficulty in obtaining accurate approximations of turgor pressure within the plant, which is more difficult to achieve than the use of perceived air temperature to express plant growth. However, a more complex approach is mandatory for accurately capturing the drought response on plant growth, and model-assisted approximations of turgor pressure are becoming prevalent in models of plant growth (Steppe et al. 2006; De Schepper \& Steppe 2010; Fatichi, Leuzinger \& Körner 2014). In order to include the strength of both temperature and turgor within the turgor-time concept, however, the interaction effects of temperature and turgor-driven growth (Figs. 5; 6) need to be better understood.

A clear temperature dependency of the model parameters was reported in the original model for both the elongation rates $\left(k_{1}\right.$ and $\left.k_{2}\right)$ and the ontogeny parameters (Durand et al. 1999; Fournier et al. 2005). Interestingly, elongation rates were reported to be unaffected by temperature when expressed in terms of thermal time, indicating a linear relationship of growth rates with temperature. However, 
were reported to have a more complex relationship with temperature, even when expressed in terms of thermal time. The effect of temperature was not investigated during the case study with the full version of the model as there was only a small difference in daytime and nighttime temperatures. However, in order to evaluate if inclusion of a temperature dependency of the model parameters could lead to similar observations of temperature-growth rate relation as in the original model (Durand et al. 1999; Fournier et al. 2005), a simple linear dependency between threshold turgor and temperature was evaluated based on the work of Proseus et al. (2000) (Fig. 5; 6). Our results indicated that this linear relationship can only lead to the linear temperature-growth rate relations found in the original ontogenetic model (Durand et al. 1999; Fournier et al. 2005) under very specific conditions. Rather, the constant growth rate per thermal time reported in the original model is an indication that there may be a linear relationship between temperature and cell wall extensibility, as extensibility serves as the linear factor relating growth and "growth-enabling turgor" (i.e. turgor above the threshold) in the irreversible part of the Lockhart equation (Eq. 3), rather than threshold turgor. The contribution of a temperature-induced change in extensibility and threshold turgor on growth are closely related, and their relationship can be determined by establishing the shift in relationship between growth rate and turgor pressure under different temperature treatments. A parallel shift of the turgor pressure - growth rate relationship with temperate can be attributed to a change in threshold turgor, while a change in the slope of the turgor pressure - growth rate relationship can be attributed to a change in cell wall extensibility. Such a distinction is difficult to determine without high quality, isolated data which may be difficult to obtain in multicellular plants, leading to varying conclusions in literature as the main determining parameter affected (e.g., threshold turgor (Boyer 1993), cell wall extensibility (Pritchard, Barlow, Adam \& Tomos 1990a), or both (Pritchard, Wyn Jones et al. 1990; Pietruszka and Lewicka 2007)). The complex relationship found between temperature and the transition rates in the original ontogenetic model (Durand et al. 1999; Fournier et al. 2005) may indicate an effect of temperature directly on specific transition factors (i.e. $\mathrm{a}_{\mathrm{dz}}^{\psi_{\mathrm{p}}}$ and $\mathrm{b}_{\mathrm{eoz}}^{\psi_{\mathrm{p}}}$ ). To a lesser 
670

671

672

673

674

675

676

677 pressure) through the van 't Hoff equation (Eq. 21) or the possibility for drought stress to decrease cell wall extensibility (Tardieu et al. 2014) are factors to consider when studying these relationships and were currently not yet included in our model.

Overall, these observations indicate a more complex interaction between temperature, turgor, yield threshold, and cell wall extensibility than can be explained by a simple linear temperature - threshold turgor relationship as explored in this paper. We believe that focussed future experiments under different treatments of both temperature and drought, combined with simulations from our model could provide deeper insight into these interrelations. Elucidating these effects could be greatly beneficial for expressing the model in terms of truly environmentally insensitive parameters, regardless of temperature and drought conditions, whereby growth is expressed uniformly in terms of turgor-time (Fig. 1). Such parameters could then be related to genotypic traits and be used to map differences in drought tolerance between genotypes or breed towards specific traits (Bertin, Martre, Génard, Quilot \& Salon 2010; Tardieu \& Tuberosa 2010). The concept of turgor-time has the potential to function as a new, general metric for uniformly expressing growth (Fig. 4).

\section{ACKNOWLEDGMENTS}

We would like to thank Research Foundation Flanders (FWO) for funding this research.

\section{DATA AVAILABILITY STATEMENT}

The data that support the findings of this study are available from the corresponding author upon reasonable request. 
691 LITERATURE

692

693

694

695

696

697

698

699

700

701

702

703

704

705

706

707

708

709

710

711

712

Acevedo E., Fereres E., Hsiao T.C. \& Henderson D.W. (1979) Diurnal Growth Trends, Water Potential, and Osmotic Adjustment of Maize and Sorghum Leaves in the Field. Plant Physiology 64, 476480.

Avramova V., Abdelgawad H., Vasileva I., Petrova A.S., Holek A., Mariën J., ... Beemster G.T.S. (2017) High antioxidant activity facilitates maintenance of cell division in leaves of drought tolerant maize hybrids. Frontiers in Plant Science 8.

Benes B., Guan K., Lang M., Long S.P., Lynch J.P., Marshall-Colón A., ... Turk M.J. (2020) Multiscale computational models can guide experimentation and targeted measurements for crop improvement. Plant Journal, 21-31.

Bertin N., Martre P., Génard M., Quilot B. \& Salon C. (2010) Under what circumstances can processbased simulation models link genotype to phenotype for complex traits? Case-study of fruit and grain quality traits. Journal of Experimental Botany 61, 955-967.

Bouchabké O., Tardieu F. \& Simonneau T. (2006) Leaf growth and turgor in growing cells of maize (Zea mays L.) respond to evaporative demand under moderate irrigation but not in watersaturated soil. Plant, Cell and Environment 29, 1138-1148.

Boyer J.S. (1993) Temperature and growth-induced water potential. Plant, Cell \& Environment 16, 1099-1106.

Bradford K.J. \& Hsiao T.C. (1982) Physiological responses to moderate water stress. In Physiological plant ecology II. pp. 263-324.

Brégard A. \& Allard G. (1999) Sink to source transition in developing leaf blades of tall fescue. New Phytologist 141, 45-50. 
Brown P.N., Byrne G.D. \& Hindmarsh A.C. (1989) VODE: a variable-coefficient ODE solver. SIAM journal on scientific and statistical computing 10, 1038-1051.

Caldeira C.F., Bosio M., Parent B., Jeanguenin L., Chaumont F. \& Tardieu F. (2014) A hydraulic model is compatible with rapid changes in leaf elongation under fluctuating evaporative demand and soil water status. Plant Physiology 164, 1718-1730.

Chaves M.M., Maroco J.P. \& Pereira J.S. (2003) Understanding plant responses to drought - From genes to the whole plant. Functional Plant Biology 30, 239-264.

Cooper M., Gho C., Leafgren R., Tang T. \& Messina C. (2014) Breeding drought-tolerant maize hybrids for the US corn-belt: Discovery to product. Journal of Experimental Botany 65, 61916194.

Cosgrove D.J. (2000) Loosening of plant cell walls by expansins. Nature 407, 321-326.

Coussement J.R., De Swaef T., Lootens P., Roldán-Ruiz I. \& Steppe K. (2018) Introducing turgor-driven growth dynamics into functional-structural plant models. Annals of Botany 121, 849-861.

Coussement J.R., De Swaef T., Lootens P. \& Steppe K. (2020) Turgor-driven plant growth applied in a soybean functional-structural plant model. Annals of Botany 126, 729-744.

Cramer G.R. (1992) Kinetics of Maize Leaf Elongation: II. Responses of a NA-excluding cultivar and a NA-including cultivar to varying NA/CA salinities. Journal of Experimental Botany 43, 857-864.

Cramer G.R. \& Bowman D.C. (1991) Kinetics of maize leaf elongation. I. Increased yield threshold limits short-term, steady-state elongation rates after exposure to salinity. Journal of Experimental Botany 42, 1417-1426.

De Pauw D.J.W., Steppe K. \& De Baets B. (2008) Identifiability analysis and improvement of a tree water flow and storage model. Mathematical biosciences 211, 314-32.

De Schepper V. \& Steppe K. (2010) Development and verification of a water and sugar transport 

model using measured stem diameter variations. Journal of Experimental Botany 61, 20832099.

Durand J.L., Onillon B., Schnyder H. \& Rademacher I. (1995) Drought effects on cellular and spatial parameters of leaf growth in tall fescue. Journal of Experimental Botany 46, 1147-1155.

Durand J.L., Schäufele R. \& Gastal F. (1999) Grass leaf elongation rate as a function of developmental stage and temperature: Morphological analysis and modelling. Annals of Botany 83, 577-588.

van Eeuwijk F.A., Bustos-Korts D., Millet E.J., Boer M.P., Kruijer W., Thompson A., ... Chapman S.C. (2019) Modelling strategies for assessing and increasing the effectiveness of new phenotyping techniques in plant breeding. Plant Science 282, 23-39.

FAO (2014) Statistical Yearbook of the Food And Agricultural Organization for the United Nations.

Fatichi S., Leuzinger S. \& Körner C. (2014) Moving beyond photosynthesis: From carbon source to sink-driven vegetation modeling. New Phytologist 201, 1086-1095.

Fournier C., Durand J.L., Ljutovac S., Schäufele R., Gastal F. \& Andrieu B. (2005) A functionalstructural model of elongation of the grass leaf and its relationships with the phyllochron. New

Fricke W. \& Flowers T.J. (1998) Control of leaf cell elongation in barley. Generation rates of osmotic pressure and turgor, and growth-associated water potential gradients. Planta 206, 53-65.

Gong F., Wu X., Zhang H., Chen Y. \& Wang W. (2015) Making better maize plants for sustainable grain production in a changing climate. Frontiers in Plant Science 6, 1-6.

Hsiao T.C., Frensch J. \& Rojas-Lara B.A. (1998) The pressure-jump technique shows maize leaf growth to be enhanced by increases in turgor only when water status is not too high. Plant, Cell and Environment 21, 33-42. 
Lockhart J.A. (1965) An analysis of irreversible plant cell elongation. Journal of Theoretical Biology 8, 264-275.

Lu Z. \& Neumann P.M. (1998) Water-stressed maize, barley and rice seedlings show species diversity in mechanisms of leaf growth inhibition. Journal of Experimental Botany 49, 1945-1952.

Luo L.J. (2010) Breeding for water-saving and drought-resistance rice (WDR) in China. Journal of Experimental Botany 61, 3509-3517.

Matsuda K. \& Riazi A. (1981) Stress-Induced Osmotic Adjustment in Growing Regions of Barley Leaves. Plant Physiology 68, 571-576.

Michelena V.A. \& Boyer J.S. (1982) Complete turgor maintenance at low water potentials in the elongating region of maize leaves. Plant Physiology 69, 1145-1149.

Munns R., James R.A., Sirault X.R.R., Furbank R.T. \& Jones H.G. (2010) New phenotyping methods for screening wheat and barley for beneficial responses to water deficit. Journal of Experimental Botany 61, 3499-3507.

Munns R. \& Weir R. (1981) Contribution of Sugars to Osmotic Adjustment in Elongating and Expanded Zones of Wheat Leaves During Moderate Water Deficits at Two Light Levels. Functional Plant Biology 8, 93.

Nelissen H., Sun X.H., Rymen B., Jikumaru Y., Kojima M., Takebayashi Y., ... Inzé D. (2018) The reduction in maize leaf growth under mild drought affects the transition between cell division and cell expansion and cannot be restored by elevated gibberellic acid levels. Plant Biotechnology Journal 16, 615-627.

Nikinmaa E., Sievänen R. \& Hölttä T. (2014) Dynamics of leaf gas exchange, xylem and phloem transport, water potential and carbohydrate concentration in a realistic 3-D model tree crown. Annals of Botany, 653-666. 
Ning P., Peng Y. \& Fritschi F.B. (2018) Carbohydrate dynamics in maize leaves and developing ears in response to nitrogen application. Agronomy 8.

Norton M.R., Malinowski D.P. \& Volaire F. (2016) Plant drought survival under climate change and strategies to improve perennial grasses. A review. Agronomy for Sustainable Development 36.

Ortega J.K.E. (1985) Augmented growth equation for cell wall expansion. Plant Physiology 79, 318320.

Pantin F., Simonneau T., Rolland G., Dauzat M. \& Muller B. (2011) Control of leaf expansion: A developmental switch from metabolics to hydraulics. Plant Physiology 156, 803-815.

Parent B., Suard B., Serraj R. \& Tardieu F. (2010) Rice leaf growth and water potential are resilient to evaporative demand and soil water deficit once the effects of root system are neutralized. Plant, Cell and Environment 33, 1256-1267.

Parrish D.J. \& Wolf D.D. (1983) Kinetics of Tall Fescue Leaf Elongation: Responses to Changes in Illumination and Vapor Pressure 1. Crop Science 23, 659-663.

Pietruszka M. \& Lewicka S. (2007) Effect of temperature on plant elongation and cell wall extensibility. General Physiology and Biophysics 26, 40-47.

Pritchard J., Barlow P.W., Adam J.S. \& Tomos A.D. (1990a) Biophysics of the inhibition of the growth of maize roots by lowered temperature. Plant Physiology 93, 222-230.

Pritchard J., Wyn Jones R.G. \& Tomos A.D. (1990b) Measurement of Yield Threshold and Cell Wall Extensibility of Intact Wheat Roots under Different Ionic, Osmotic and Temperature Treatments. Journal of Experimental Botany 41, 669-675.

Proseus T.E., Zhu G.L. \& Boyer J.S. (2000) Turgor, temperature and the growth of plant cells: Using Chara corallina as a model system. Journal of Experimental Botany 51, 1481-1494.

R Core Team (2016) R: A language and environment for statistical computing. Vienna, Austria. 
Sarlikioti V., de Visser P.H.B., Buck-sorlin G.H. \& Marcelis L.F.M. (2011) How plant architecture affects light absorption and photosynthesis in tomato: towards an ideotype for plant architecture using a functional-structural plant model. Annals of botany 108, 1065-73.

Schnyder H. \& Nelson C.J. (1988) Diurnal Growth of Tall Fescue Leaf Blades. Plant Physiology 86, 1070-1076.

Sicher R., Kremer D. \& Harris W. (1984) Diurnal carbohydrate metabolism of barley primary leaves. Plant physiology 76, 165-169.

Skinner R.H. \& Nelson C.J. (1995) Elongation of the Grass Leaf and its Relationship to the Phyllochron. Crop Science 35, 4-10.

Soetaert K., Petzoldt T. \& Setzer R. (2010a) deSolve: General solvers for initial value problems of

Soetaert K., Petzoldt T. \& Setzer R.W. (2010b) Solving differential equations in R: Package deSolve. Journal of Statistical Software 33, 1-25.

Tang A.C. \& Boyer J.S. (2002) Growth-induced water potentials and the growth of maize leaves. Journal of Experimental Botany 53, 489-503. Knowledge. Current Biology 27, R770-R783. 

transpiration and plant growth and cannot be simply deduced from short-term mechanisms. Plant Cell and Environment 40, 846-857.

Tardieu F., Parent B., Caldeira C.F. \& Welcker C. (2014) Genetic and physiological controls of growth under water deficit. Plant Physiology 164, 1628-1635.

Tardieu F., Reymond M., Hamard P., Granier C. \& Muller B. (2000) Spatial distributions of expansion rate, cell division rate and cell size in maize leaves: A synthesis of the effects of soil water status, evaporative demand and temperature. Journal of Experimental Botany 51, 1505-1514.

Tardieu F. \& Tuberosa R. (2010) Dissection and modelling of abiotic stress tolerance in plants. Current Opinion in Plant Biology 13, 206-212.

Thomas H., James A.R. \& Humphreys M.W. (1999) Effects of water stress on leaf growth in tall fescue, Italian ryegrass and their hybrid: Rheological properties of expansion zones of leaves,

Trudgill D.L., Honek A., Li D. \& Van Straalen N.M. (2005) Thermal time - Concepts and utility. Annals measured on growing and killed tissue. Journal of Experimental Botany 50, 221-231.

Westgate M.E. \& Boyer J.S. (1985) Osmotic adjustment and the inhibition of leaf, root, stem and silk growth at low water potentials in maize. Planta, 540-549.

Yin X., Goudriaan J., Lantinga E.A., Vos J. \& Spiertz H.J. (2003) A flexible sigmoid function of determinate growth. Annals of Botany 91, 361-371.

Zheng Y., Xu M., Hou R., Shen R., Qiu S. \& Ouyang Z. (2013) Effects of experimental warming on stomatal traits in leaves of maize (Zea may L.). Ecology and Evolution 3, 3095-3111. 
851

852

853

854

855 


\begin{tabular}{|c|c|c|c|c|}
\hline \multicolumn{5}{|c|}{ Measured parameters } \\
\hline Parameter & $\begin{array}{l}\text { Value ( } \pm 95 \% \\
\text { conf) }\end{array}$ & Unit & Description & $\begin{array}{l}\text { Reference } \\
\text { values }\end{array}$ \\
\hline $\mathbf{E}_{\text {leaf }}$ & $173 \pm 102$ & $\mathrm{~g} \mathrm{~m}^{-2} \mathrm{~h}^{-1}$ & $\begin{array}{l}\text { Maximal transpiration } \\
\text { rate per leaf area }\end{array}$ & $194^{1}$ \\
\hline$A_{\text {canopy }}^{\mathrm{V} 3}$ & $0.066 \pm 0.034$ & $\mathrm{~m}^{2}$ & $\begin{array}{l}\text { Total leaf area at the V3 } \\
\text { stage }\end{array}$ & - \\
\hline $\mathbf{f}_{\text {shape }}$ & 0.9 & - & $\begin{array}{l}\text { Fractional leaf area } \\
\text { when compared to a } \\
\text { rectangle with the same } \\
\text { length / width ratio }\end{array}$ & - \\
\hline \multicolumn{5}{|c|}{ Assumed parameters } \\
\hline$\Psi_{0, l e a f}^{w w}$ & -0.6 & $\mathrm{MPa}$ & $\begin{array}{l}\text { Leaf osmotic potential } \\
\text { under well-watered } \\
\text { conditions }\end{array}$ & $-0.8^{2} ;-0.6^{3}$ \\
\hline $\mathrm{C}_{\text {canopy }}$ & 10 & $\mathrm{~g} \mathrm{MPa}^{-1}$ & $\begin{array}{l}\text { Previously established } \\
\text { canopy capacitance }\end{array}$ & -4 \\
\hline $\mathrm{C}_{\text {stem }}$ & 15 & $\mathrm{~g} \mathrm{MPa}^{-1}$ & $\begin{array}{l}\text { Stem segment } \\
\text { capacitance }\end{array}$ & -4 \\
\hline $\mathbf{E}_{\text {canopy }}$ & 12.5 & $\mathrm{~g} \mathrm{~h}^{-1}$ & $\begin{array}{l}\text { Previously established } \\
\text { canopy max } \\
\text { transpiration rate }\end{array}$ & -4 \\
\hline$\varepsilon_{D_{\mathrm{z}}}$ & 1 & $\mathrm{MPa}$ & $\begin{array}{l}\text { Elasticity of cells in the } \\
\text { division zone }\end{array}$ & 1 (ryegrass $\left.^{5}\right)$ \\
\hline$\varepsilon_{\mathrm{E}_{\mathrm{oz}}}$ & 1 & $\mathrm{MPa}$ & $\begin{array}{l}\text { Elasticity of cells in the } \\
\text { elongation-only zone }\end{array}$ & 1 (ryegrass $^{5}$ ) \\
\hline$\varepsilon_{M_{\mathrm{z}}}$ & 10 & $\mathrm{MPa}$ & $\begin{array}{l}\text { Elasticity of cells in the } \\
\text { mature zone }\end{array}$ & 20 (ryegrass $\left.^{5}\right)$ \\
\hline $\mathbf{W}_{\text {canopy }}^{\max }$ & 100 & g & $\begin{array}{l}\text { Previously established } \\
\text { canopy water content }\end{array}$ & -4 \\
\hline $\mathbf{W}_{\text {stem }}^{\max }$ & 100 & g & $\begin{array}{l}\text { Stem segment water } \\
\text { content }\end{array}$ & -4 \\
\hline \multicolumn{5}{|c|}{ Calibrated parameters: plant characteristics } \\
\hline c & 0.90 & dimensionless & $\begin{array}{l}\text { Capacity for osmotic } \\
\text { adjustment }\end{array}$ & - \\
\hline $\mathbf{R}_{\text {soil } \rightarrow \text { stem }}^{\mathbf{X}}$ & 0.098 & $\mathrm{MPa} \mathrm{g}^{-1} \mathrm{~h}$ & $\begin{array}{l}\text { Xylem transport } \\
\text { resistance from soil to } \\
\text { stem segment }\end{array}$ & - \\
\hline $\mathbf{R}_{\text {stem } \rightarrow \text { canopy }}^{\mathrm{X}}$ & 0.196 & $\mathrm{MPa}^{-1} \mathrm{~h}$ & $\begin{array}{l}\text { Xylem transport } \\
\text { resistance from stem } \\
\text { segment to previously } \\
\text { established canopy }\end{array}$ & - \\
\hline $\mathbf{R}_{\text {stem } \rightarrow \text { leaf }}^{\mathbf{X}}$ & 0.203 & $\mathrm{MPa}^{-1} \mathrm{~h}$ & $\begin{array}{l}\text { Xylem transport } \\
\text { resistance from stem }\end{array}$ & - \\
\hline
\end{tabular}




\begin{tabular}{|c|c|c|c|c|}
\hline & & & $\begin{array}{l}\text { segment to developing } \\
\text { leaf }\end{array}$ & \\
\hline$\Gamma$ & 0.2 & $\mathrm{MPa}$ & Threshold turgor & 6 \\
\hline \multicolumn{5}{|c|}{ Calibrated parameters: leaf ontogeny } \\
\hline$a_{d z}^{\Psi_{p}}$ & 0.0535 & $\mathrm{MPa}^{-1} \mathrm{~h}^{-1}$ & $\begin{array}{l}\text { Rate of transition speed } \\
\text { increase from DZ to } \\
\text { EOZ with turgor-time }\end{array}$ & - \\
\hline $\mathbf{b}_{\mathrm{eoz}}^{\Psi_{\mathrm{p}}}$ & 0.0254 & $\mathrm{MPa}^{-1} \mathrm{~h}^{-1}$ & $\begin{array}{l}\text { Rate of transition speed } \\
\text { increase from EOZ to } \\
\text { MZ with turgor-time }\end{array}$ & - \\
\hline$t_{a}^{\Psi_{p}}$ & 16.87 & $\mathrm{MPa} \mathrm{h}$ & $\begin{array}{l}\text { Turgor-time from leaf } \\
\text { initiation to beginning } \\
\text { of transition from DZ to } \\
\text { EOZ }\end{array}$ & - \\
\hline$t_{b}^{\Psi_{p}}$ & 4.91 & $\mathrm{MPa} \mathrm{h}$ & $\begin{array}{l}\text { Turgor-time from leaf } \\
\text { initiation to beginning } \\
\text { of transition from EOZ } \\
\text { to } \mathrm{MZ}\end{array}$ & - \\
\hline \multicolumn{5}{|c|}{ Calibrated parameters: Leaf zone biophysical properties } \\
\hline $\mathbf{D}_{\mathrm{Z}}$ (init) & 0.000917 & $m$ & $\begin{array}{l}\text { Initial length of the } \\
\text { division zone }\end{array}$ & - \\
\hline$\phi_{\mathbf{D}_{\mathbf{z}}}$ & 0.112 & $\mathrm{MPa}^{-1} \mathrm{~h}^{-1}$ & $\begin{array}{l}\text { Extensibility (i.e. plastic } \\
\text { compliance) of the cells } \\
\text { in the division zone }\end{array}$ & $\begin{array}{l}0.03-0.8 \\
\text { (volumetric }^{7} \text { ) }\end{array}$ \\
\hline$\phi_{\mathrm{E}_{\mathrm{oz}}}$ & 0.338 & $\mathrm{MPa}^{-1} \mathrm{~h}^{-1}$ & $\begin{array}{l}\text { Extensibility of the cells } \\
\text { in the elongation-only } \\
\text { zone }\end{array}$ & $\begin{array}{l}0.03-0.8 \\
\text { (volumetric } 7 \text { ) }\end{array}$ \\
\hline$\phi_{M_{z}}$ & 0 & $\mathrm{MPa}^{-1} \mathrm{~h}^{-1}$ & $\begin{array}{l}\text { Extensibility of the cells } \\
\text { in the mature zone }\end{array}$ & - \\
\hline
\end{tabular}
potential based on estimated canopy transpiration. entire growing zone is reported. 
$867{ }^{7}$ (Hsiao, Frensch \& Rojas-Lara 1998), distinction between DZ and EOZ not made, though different 868 stages of leaf elongation are considered. Very young leaves (20-30 mm exposed length) are reported to have a lower extensibility than elongating leaves (30-50 $\mathrm{mm}$ exposed length). Young leaves are reported as 0.2 while elongating leaves go up to 0.8 on average. Volumetric extensibility has been

871 reported and should be considered the sum of the all extensibility components (including width and

872 thickness directions)

873

874 
Fig. 1: Conceptual representation of how the concept of turgor-time, combined with a temperaturedependent threshold turgor, could potentially lead to a uniform expression of growth across both drought and temperature treatments as opposed to thermal time, which is only valid for temperature treatments. The top figures display how daily patterns of turgor (A1; B1; $\mathrm{C} 1)$ and temperature $(\mathrm{A} 2 ; \mathrm{B} 2$; C2) contribute to turgor-time and thermal time respectively (green area), with variations in night (dark blue area) and day hours (light blue area). Growth under non-stressed conditions (B) results in a logistic growth pattern in the long term, whether it be expressed in real time (B3); thermal time (B4) or turgor-time (B5). A reduction in temperature results in diminished growth, leading to a deviation in the growth curve when expressed in real time (C3). However, the reduction in temperature also slows the progression of thermal time (C2) which means the same growth curve can be used to describe growth when expressed in thermal time (B4; C4) regardless of temperature treatment. Using the inverse relation between temperature and threshold turgor (C1) the same rationale holds true for the growth curve expressed in turgor-time (C5). A reduction in soil water potential, however, results in a reduction in real time growth $(\mathrm{A} 1 ; \mathrm{A} 3)$ without affecting the perceived thermal time $(\mathrm{A} 2)$. As a result, the universal growth curve in terms of thermal time $(B 4 ; C 4)$ is no longer valid under drought-stressed conditions (A4). Turgor-time, however, can capture both effects to create a single, valid growth curve (A5; B5; C5).

Fig. 2: Simulated progression of leaf length and individual leaf growth zones of the calibrated model ( $A$ and $C$ ) plotted on top of measured division zone and total leaf length for maize grown under control conditions (soil water potential -0.02 MPa). B and D represent an identical simulation with altered soil water potential (-0.52 MPa) plotted on top of measured division zone and total leaf length of maize leaves grown under mild water stress, with the control treatment plotted in dashed lines (and its data plotted in grey). The dark bars represent the nighttime hours over the course of the leaf development. Overall, growth is slower within the mild drought treatment but continues longer due to slower transitioning between the zones. This is also apparent in the patterns of leaf elongation rate (LER) for 
900

901

902

903

904

905

906

907

908

909

910

911

912

913

914

915

916

917

918

919

921

922

the control $(\mathrm{E})$ and mild drought $(\mathrm{F})$ treatment, plotted in terms of their average for day and nighttime hours.

Fig. 3: Theoretical simulations of leaf elongation rates (LER), averaged for every light and dark period under various conditions of drought stress. Control conditions in each panel (black) represent the LER pattern under a stable soil water potential $\left(\psi_{\mathrm{s}}\right)$ of -0.05 (black). A) Comparison to drought conditions in which $\psi_{\mathrm{s}}$ was further reduced to -0.50 (blue), and -1.50 (red) MPa. B) Comparison where $\psi_{\mathrm{s}}$ was reduced to $-0.75 \mathrm{MPa}$ with rewatering (i.e. $\psi_{\mathrm{s}}$ recovered to $-0.05 \mathrm{MPa}$ ) between 84 and $150^{\circ} \mathrm{Cd}$ (blue) and 350 and $450^{\circ} \mathrm{Cd}(\mathrm{red})$. C) Effect of transpiration rate on LER when the normal transpiration rate is halved (blue) or doubled (red). D) Drought scenario with reduced $\psi_{\mathrm{s}}$ to $-0.75 \mathrm{MPa}$ (blue) with normal transpiration compared to a scenario in which the plant closes stomata to reduce water loss due to transpiration by half (red).

Fig. 4: Comparison of the leaf elongation pattern in control and two drought stress scenarios (soil water potential $\left(\psi_{\mathrm{s}}\right)-0.05 \mathrm{MPa}(\mathrm{A} ; \mathrm{B}) ;-1.50 \mathrm{MPa}(\mathrm{C} ; \mathrm{D})$; and -2.50 MPa $(\mathrm{E} ; \mathrm{F})$ ) when identical simulations are expressed in thermal time $(A ; C ; E)$ and in turgor-time $(B ; D ; F)$. The dark bars represent the nighttime hours over the course of leaf development. Their size is also affected by the chosen time unit as turgor-time will vary over treatments and development stages, but temperature (and thus thermal time) remains unchanged. As expected, final leaf length is affected by a reduction in $\psi_{\mathrm{s}}$ in the simulations. In terms of elongation timing, the growth pattern depends on the unit of time used. When expressed in thermal time, leaf elongation under drought stress is slowed down while the duration is increased. As a result, final leaf length in the three treatments is reached at approximately $300(\mathrm{~A})$; 500 (C); and $900{ }^{\circ} \mathrm{Cd}(\mathrm{E})$. Leaf length expressed in turgor-time, however, results in near-identical patterns of leaf length progression, with the final leaf length reached at approximately $75 \mathrm{MPa} h$ in all treatments (B; D; F).

Fig. 5: Simulated relative growth rate per unit thermal time $\left(\mathrm{V} \%{ }^{\circ} \mathrm{Cd}^{-1}\right)$ in an individual cell according to the Lockhart equation for different temperatures and different linear effects of temperature on 
threshold turgor. A stable turgor pressure of $0.6 \mathrm{MPa}$ is assumed with a threshold turgor of $0.2 \mathrm{MPa}$ at $24{ }^{\circ} \mathrm{C}$ and an extensibility of $1 \mathrm{MPa}^{-1}$. The $\mathrm{Y}$-axis represents the relative threshold turgor increase/decrease at a single degree decrease/increase in temperature respectively assuming a linear relation (i.e. 0 represents no effect of temperature on threshold turgor, 0.1 means a $10 \%$ decrease in threshold turgor per $1^{\circ} \mathrm{C}$ ). The white dashed line represents the cut-off at which growth is no longer possible (i.e. $\Gamma(\mathrm{T})=0.6 \mathrm{MPa})$. The black dashed line represents the slope value for which the growth rate per unit thermal time is equal for all temperatures (i.e. $-0.01667 \mathrm{MPa}^{\circ} \mathrm{C}^{-1}$; or an $8.333 \%$ increase (res. decrease) in threshold turgor per one-degree decrease (res. increase) in temperature). As an extensibility value of 1 was chosen, this figure also represents the relation between turgor-time per unit thermal time for this system.

Fig. 6: Simulated relative growth rate per unit thermal time $\left(\mathrm{V} \%{ }^{\circ} \mathrm{Cd}^{-1}\right)$ in an individual cell according to the Lockhart equation for different temperatures and turgor pressures, with identical assumption as in Fig. 5 and the stable slope value (i.e. $-0.01667 \mathrm{MPa}^{\circ} \mathrm{C}^{-1}$ ) under $0.6 \mathrm{MPa}$ turgor conditions (black dashed line in Fig. 5). The white dashed line represents the cut-off under which no growth is possible (i.e. $\psi_{p}=\Gamma(T)$ ). This figure represents the combined effect of water availability and temperature on the growth rate per unit thermal time, assuming a linear relationship between temperature and threshold turgor. Additionally, as an extensibility value of 1 was chosen, this figure shows the relationship between turgor-time and thermal time under different treatments of water availability.

Fig. 7: Evolution of water potential components and leaf growth of a developing leaf based on different assumptions for osmotic potential. A; B) Assumption of a stable osmotic potential throughout leaf development as used during the simulations in this paper. C; D) A fixed diurnal pattern of osmotic potential. E; F) A weighted diurnal pattern based on the current fraction of mature leaf within the developing leaf. The diurnal patterns assume osmotic concentration increase due to import of solutes to reach a maximum at sunset and consumption of solutes due to growth during the night cause a minimum at sunrise. The weighted pattern is based on observations of a constant osmotic potential 
950 in the DZ. One of the major results of introducing such a diurnal pattern is the turgor pressure 951 accumulation around sunset. In the early growth stages, this turgor accumulation results in an increase 952 in instantaneous growth (D; F), but this is no longer the case in the mature leaf where the extensibility 953 is zero. As a result, this accumulation of turgor results in a reversed pressure gradient and reversed 954 water flow from leaf towards stem. This translates to leaf shrinkage starting already during the dark 955 hours (D; F) rather than the light period (B) where shrinkage is triggered by transpirational water loss. 
958 SUPPLEMENTARY MATERIAL S1: Extension of the turgor-driven leaf elongation model to 959 incorporate 3D growth

960 SUPPLEMENTARY MATERIAL S2: Detailed derivation of the equation for the change in turgor

961 pressure

962 SUPPLEMENTARY MATERIAL S3: Sensitivity of the calibrated model in control and drought

963 scenarios 
Summary statement:

A model for grass leaf elongation is presented which combines mechanistic growth based on turgor pressure and leaf ontogeny. An inverse relation was found between the rate and duration of the elongation rate, allowing for uniform expression of growth in terms of a new concept called "turgortime". 

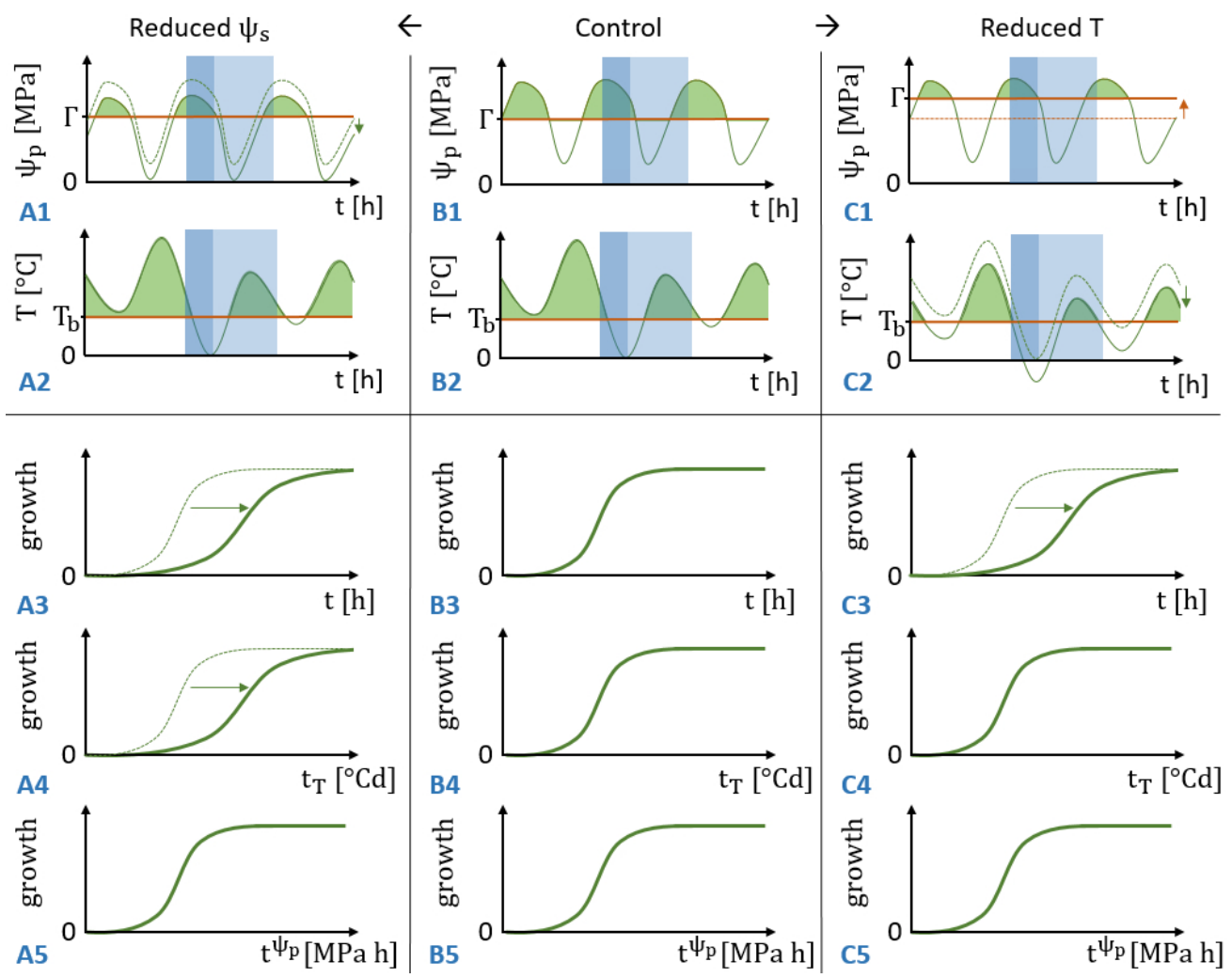

Conceptual representation of how the concept of turgor-time, combined with a temperature-dependent threshold turgor, could potentially lead to a uniform expression of growth across both drought and temperature treatments as opposed to thermal time, which is only valid for temperature treatments. The top figures display how daily patterns of turgor $(\mathrm{A} 1 ; \mathrm{B} 1 ; \mathrm{C} 1)$ and temperature $(\mathrm{A} 2 ; \mathrm{B} 2 ; \mathrm{C} 2)$ contribute to turgortime and thermal time respectively (green area), with variations in night (dark blue area) and day hours (light blue area). Growth under non-stressed conditions (B) results in a logistic growth pattern in the long term, whether it be expressed in real time (B3); thermal time (B4) or turgor-time (B5). A reduction in temperature results in diminished growth, leading to a deviation in the growth curve when expressed in real time (C3). However, the reduction in temperature also slows the progression of thermal time (C2) which means the same growth curve can be used to describe growth when expressed in thermal time (B4; C4) regardless of temperature treatment. Using the inverse relation between temperature and threshold turgor (C1) the same rationale holds true for the growth curve expressed in turgor-time (C5). A reduction in soil water potential, however, results in a reduction in real time growth (A1;A3) without affecting the perceived thermal time (A2). As a result, the universal growth curve in terms of thermal time (B4; C4) is no longer valid under drought-stressed conditions (A4). Turgor-time, however, can capture both effects to create a single, valid growth curve (A5; B5; C5). 

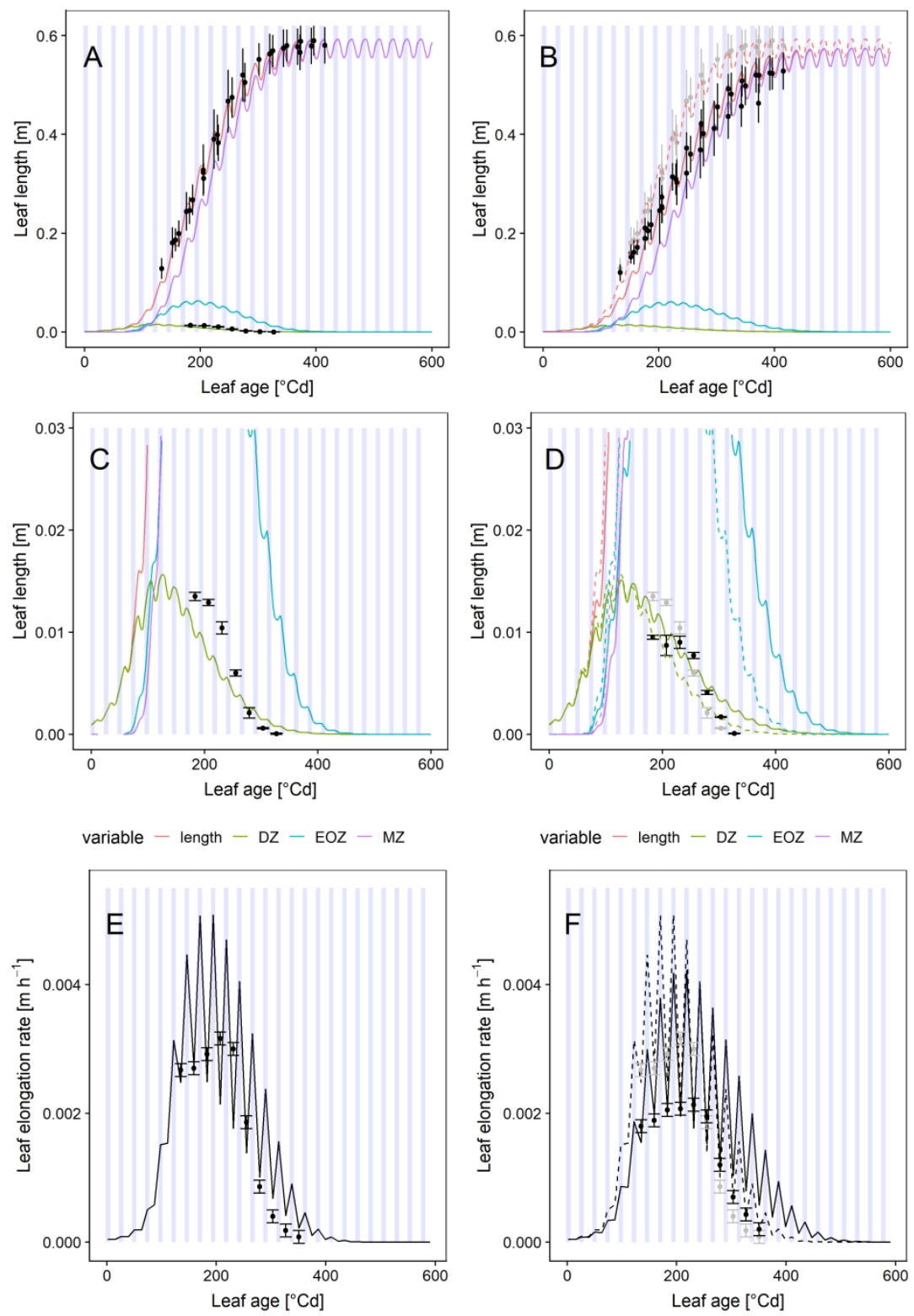

Simulated progression of leaf length and individual leaf growth zones of the calibrated model ( $A$ and $C$ ) plotted on top of measured division zone and total leaf length for maize grown under control conditions (soil water potential $-0.02 \mathrm{MPa}$ ). B and D represent an identical simulation with altered soil water potential $(-0.52$ $\mathrm{MPa}$ ) plotted on top of measured division zone and total leaf length of maize leaves grown under mild water stress, with the control treatment plotted in dashed lines (and its data plotted in grey). The dark bars represent the nighttime hours over the course of the leaf development. Overall, growth is slower within the mild drought treatment but continues longer due to slower transitioning between the zones. This is also apparent in the patterns of leaf elongation rate (LER) for the control (E) and mild drought (F) treatment, plotted in terms of their average for day and nighttime hours. 

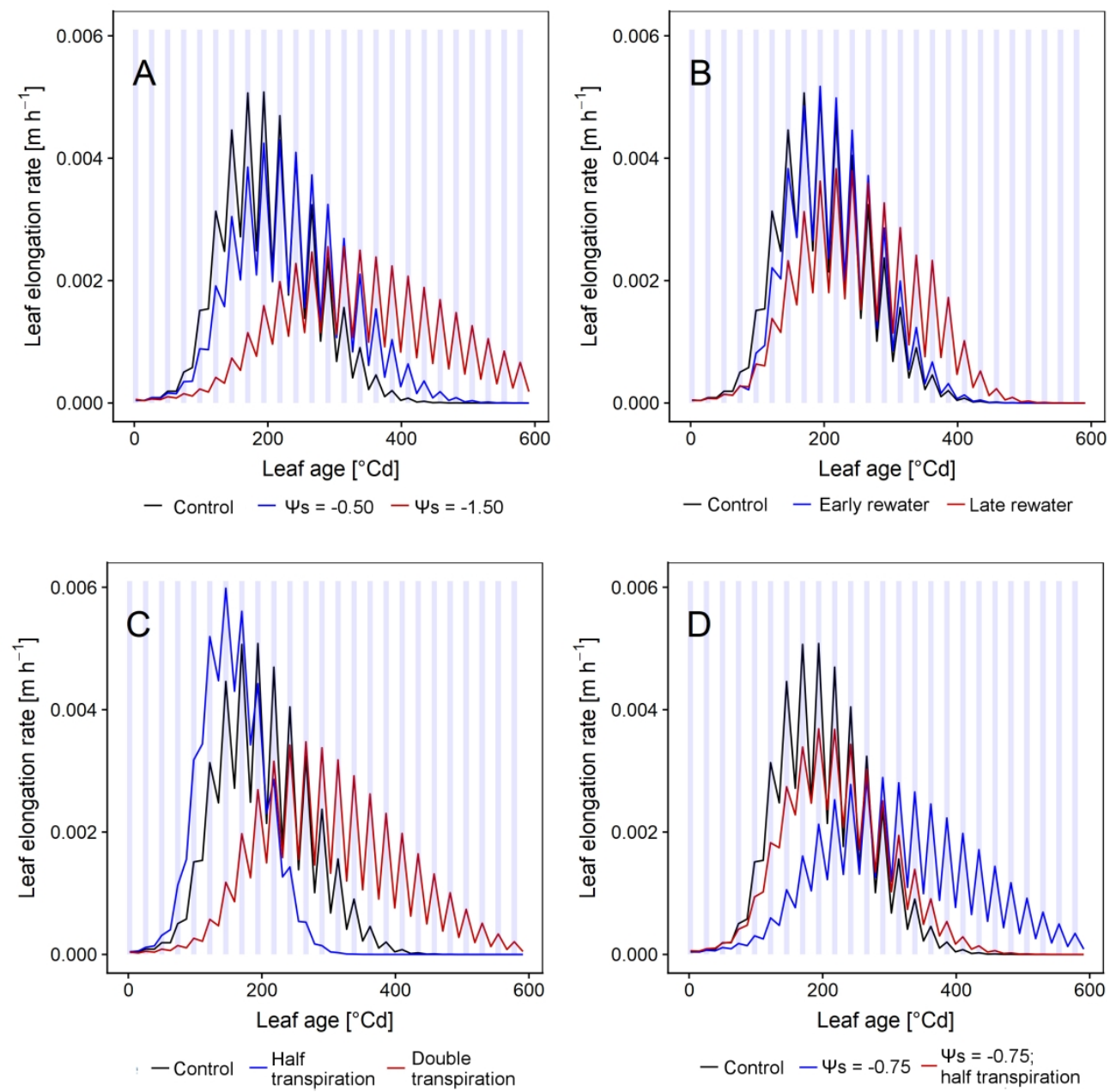

Theoretical simulations of leaf elongation rates (LER), averaged for every light and dark period under various conditions of drought stress. Control conditions in each panel (black) represent the LER pattern under a stable soil water potential ( $\psi_{-}$S) of -0.05 (black). A) Comparison to drought conditions in which $\psi$ _s was further reduced to -0.50 (blue), and -1.50 (red) MPa. B) Comparison where $\psi$ _s was reduced to -0.75 $\mathrm{MPa}$ with rewatering (i.e. $\psi_{\text {_S }}$ ( recovered to $-0.05 \mathrm{MPa}$ ) between 84 and $150^{\circ} \mathrm{Cd}$ (blue) and 350 and $450^{\circ} \mathrm{Cd}$ (red). C) Effect of transpiration rate on LER when the normal transpiration rate is halved (blue) or doubled (red). D) Drought scenario with reduced $\psi_{-} \mathrm{s}$ to $-0.75 \mathrm{MPa}$ (blue) with normal transpiration compared to a scenario in which the plant closes stomata to reduce water loss due to transpiration by half (red). 

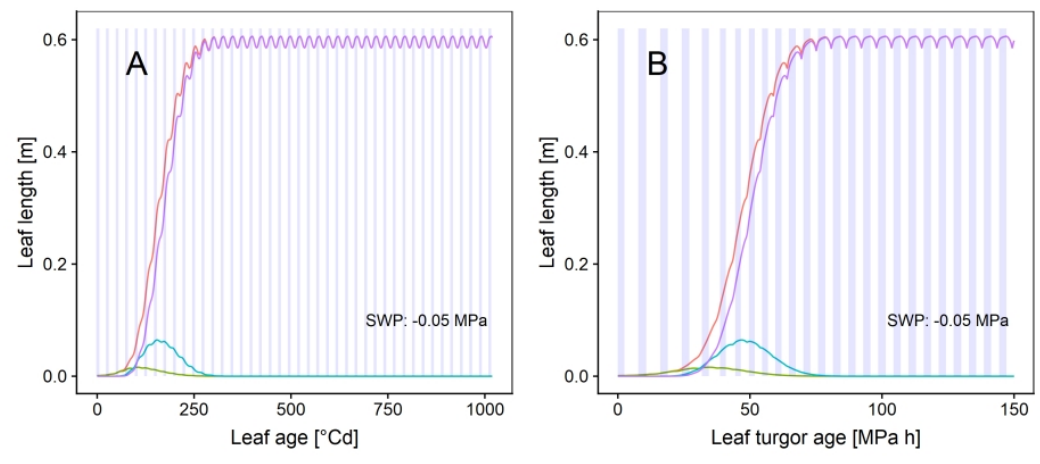

variable - length $-\mathrm{DZ}-\mathrm{EOZ}-\mathrm{MZ}$

variable - length $-\mathrm{DZ}-\mathrm{EOZ}-\mathrm{MZ}$
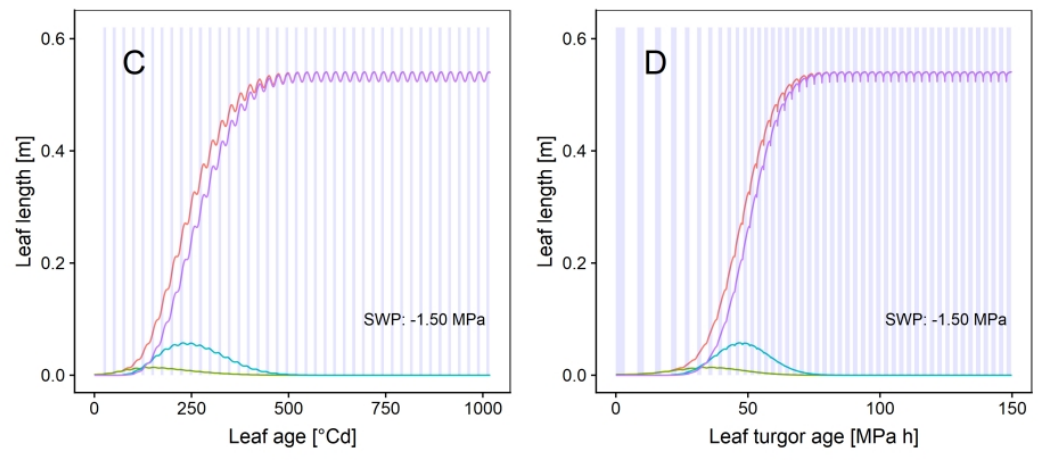

variable - length $-\mathrm{DZ}-\mathrm{EOZ}-\mathrm{MZ}$

variable - length $-\mathrm{DZ}-\mathrm{EOZ}-\mathrm{MZ}$
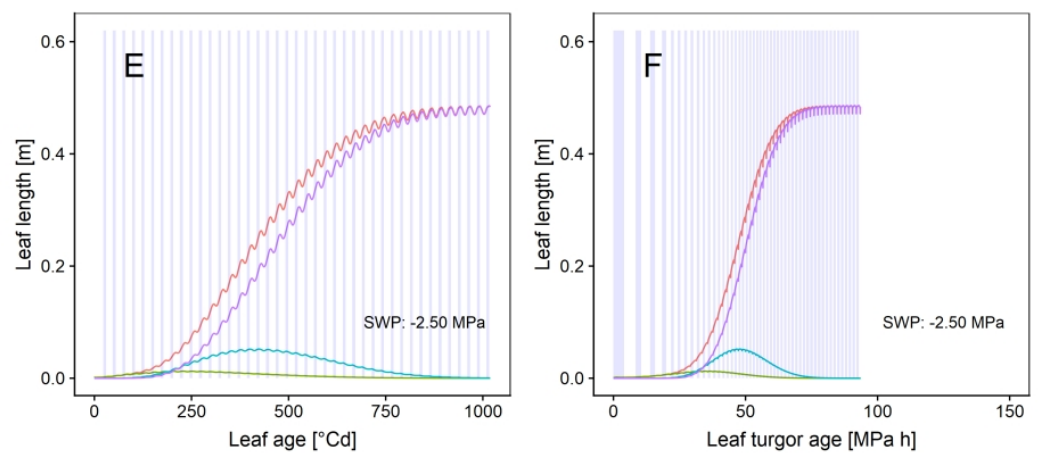

variable - length $-\mathrm{DZ}-\mathrm{EOZ}-\mathrm{MZ}$

variable - length $-\mathrm{DZ}-\mathrm{EOZ}-\mathrm{MZ}$

Comparison of the leaf elongation pattern in control and two drought stress scenarios (soil water potential $\left(\Psi \_\mathrm{S}\right)-0.05 \mathrm{MPa}(\mathrm{A} ; \mathrm{B}) ;-1.50 \mathrm{MPa}(\mathrm{C} ; \mathrm{D})$; and $-2.50 \mathrm{MPa}(\mathrm{E} ; \mathrm{F})$ ) when identical simulations are expressed in thermal time $(A ; C ; E)$ and in turgor-time $(B ; D ; F)$. The dark bars represent the nighttime hours over the course of leaf development. Their size is also affected by the chosen time unit as turgor-time will vary over treatments and development stages, but temperature (and thus thermal time) remains unchanged. As expected, final leaf length is affected by a reduction in $\psi_{-} S$ in the simulations. In terms of elongation timing, the growth pattern depends on the unit of time used. When expressed in thermal time, leaf elongation under drought stress is slowed down while the duration is increased. As a result, final leaf length

in the three treatments is reached at approximately $300(\mathrm{~A}) ; 500(\mathrm{C})$; and $900{ }^{\circ} \mathrm{Cd}(\mathrm{E})$. Leaf length expressed in turgor-time, however, results in near-identical patterns of leaf length progression, with the final leaf length reached at approximately $75 \mathrm{MPa} h$ in all treatments $(B ; D ; F)$. 


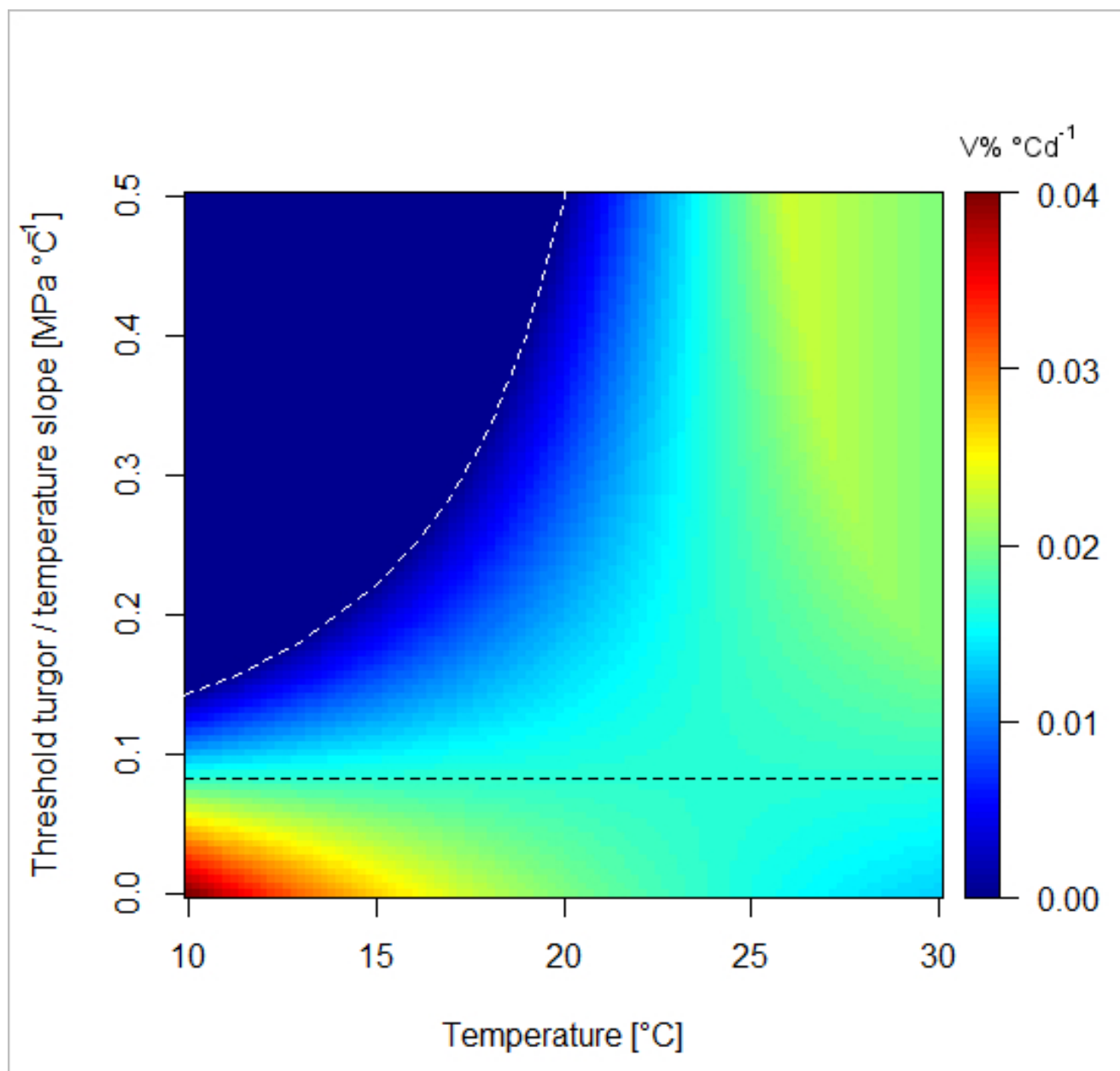

Simulated relative growth rate per unit thermal time $\left(\mathrm{V} \%{ }^{\circ} \mathrm{Cd}-1\right)$ in an individual cell according to the Lockhart equation for different temperatures and different linear effects of temperature on threshold turgor.

A stable turgor pressure of $0.6 \mathrm{MPa}$ is assumed with a threshold turgor of $0.2 \mathrm{MPa}$ at $24{ }^{\circ} \mathrm{C}$ and an extensibility of $1 \mathrm{MPa}-1$. The $\mathrm{Y}$-axis represents the relative threshold turgor increase/decrease at a single degree decrease/increase in temperature respectively assuming a linear relation (i.e. 0 represents no effect of temperature on threshold turgor, 0.1 means a $10 \%$ decrease in threshold turgor per $\left.1^{\circ} \mathrm{C}\right)$. The white dashed line represents the cut-off at which growth is no longer possible (i.e. $\Gamma(\mathrm{T})=0.6 \mathrm{MPa}$ ). The black dashed line represents the slope value for which the growth rate per unit thermal time is equal for all temperatures (i.e. $-0.01667 \mathrm{MPa}{ }^{\circ} \mathrm{C}-1$; or an $8.333 \%$ increase (res. decrease) in threshold turgor per onedegree decrease (res. increase) in temperature). As an extensibility value of 1 was chosen, this figure also represents the relation between turgor-time per unit thermal time for this system. 


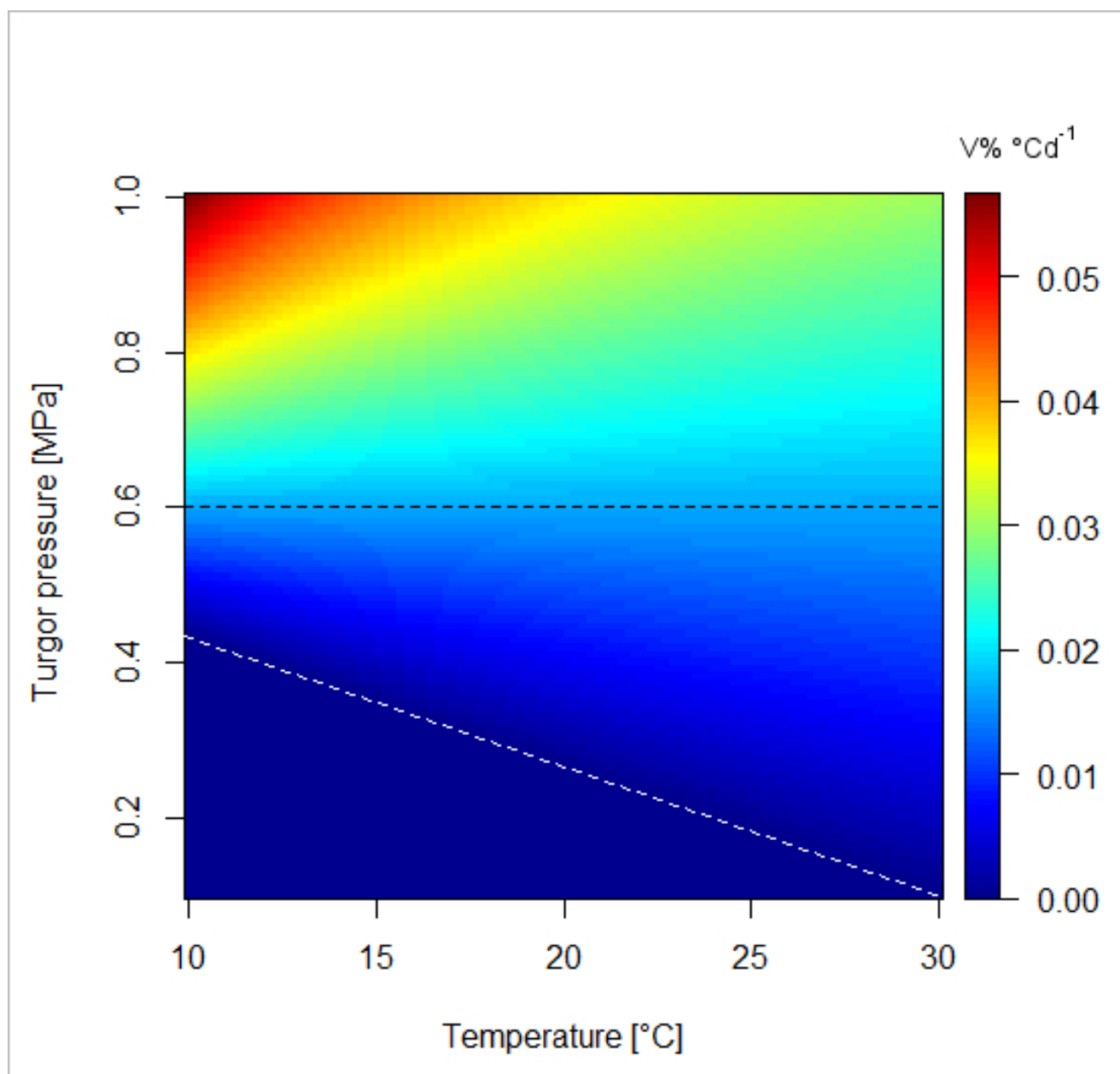

Simulated relative growth rate per unit thermal time $\left(\mathrm{V} \%{ }^{\circ} \mathrm{Cd}-1\right)$ in an individual cell according to the Lockhart equation for different temperatures and turgor pressures, with identical assumption as in Fig. 5 and the stable slope value (i.e. $-0.01667 \mathrm{MPa}{ }^{\circ} \mathrm{C}-1$ ) under $0.6 \mathrm{MPa}$ turgor conditions (black dashed line in Fig. 5 ). The white dashed line represents the cut-off under which no growth is possible (i.e. $\Psi \_p=\Gamma(T)$ ). This figure represents the combined effect of water availability and temperature on the growth rate per unit thermal time, assuming a linear relationship between temperature and threshold turgor. Additionally, as an extensibility value of 1 was chosen, this figure shows the relationship between turgor-time and thermal time under different treatments of water availability. 

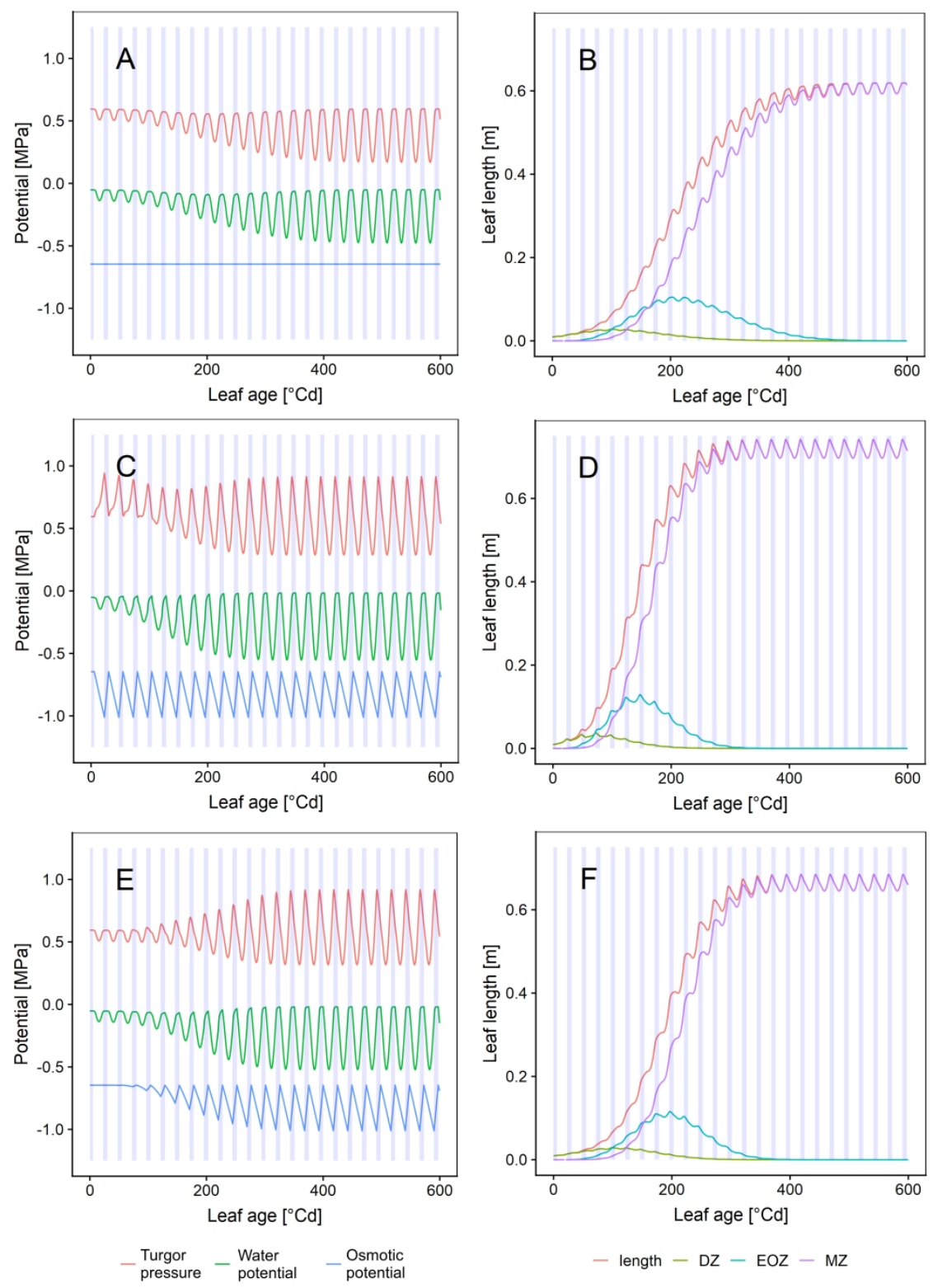

Evolution of water potential components and leaf growth of a developing leaf based on different assumptions for osmotic potential. A; B) Assumption of a stable osmotic potential throughout leaf development as used during the simulations in this paper. C; D) A fixed diurnal pattern of osmotic potential. E; F) A weighted diurnal pattern based on the current fraction of mature leaf within the developing leaf. The diurnal patterns assume osmotic concentration increase due to import of solutes to reach a maximum at sunset and consumption of solutes due to growth during the night cause a minimum at sunrise. The weighted pattern is based on observations of a constant osmotic potential in the DZ. One of the major results of introducing such a diurnal pattern is the turgor pressure accumulation around sunset. In the early growth stages, this turgor accumulation results in an increase in instantaneous growth ( $D ; F)$, but this is no longer the case in the mature leaf where the extensibility is zero. As a result, this accumulation of turgor results in an reversed pressure gradient and negative water flow from leaf towards stem. This translates to leaf shrinkage starting already during the dark hours (D; F) rather than the light period (B) where shrinkage is triggered by transpirational water loss. 
Page 55 of 5 (a) Environ

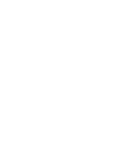

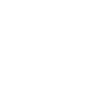

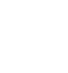

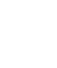

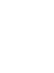

(1)

(1)

(1) 